Presented at the Annual Illuminating Engineering Society

Improving the Performance of Photo-Electrically Controlled Lighting Systems

Francis Rubinstein, Greg Ward and Rudy Verderber

Lighting Systems Research Group

Energy \& Environment Division

Lawrence Berkeley Laboratory

Berkeley, California 94720

August 1988

This work was supported by the Assistant Secretary for Conservation and Renewable Energy, Office of Building Technologies, Building Equipment Division of the U.S. Department of Energy under Contract No. DE-ACO3-76SFOOO98. 


\author{
Improving the Performance of \\ Photo-Electrically Controlled Lighting Systems \\ Francis Rubinstein \\ Gregory Ward \\ Rudy Verderber \\ Lawrence Berkeley Laboratory \\ Lighting Systems Research Group \\ Building 90, Room 3111 \\ Berkeley, CA 94720 \\ (415) 486-4096
}

\begin{abstract}
ARSTRACT
The ability of a photo-electrically controlled lighting system to maintain a constant total light level on a task surface by responding to changing daylight leveis is affected by the control algorithm used to relate the photosensor signal to the supplied electric light level and by the placement and geometry of the photosensor. We describe the major components of a typical control system, discuss the operation of three different control algorithms, and derive expressions for each algorithm that express the total illuminance at the task as a function of the control photosensor signal. Using a specially-designed scale model, we measured the relationship between the signal generated by various ceiling-mounted control photosensors and workplane illuminance for two room geometries under real sky conditions. The measured data were used to determine the performance of systems obeying the three control algorithms under varying daylight conditions. Control systems employing the commonly-used integral reset algorithm supplied less electric light than required, failing to satisfy the control objective regardless of the control photosensor used. Systems employing an alternative, closed-loop proportional control algorithm acheived the control objective under virtually all tested conditions when operated by a ceiling-mounted photosensor shielded from direct window light.
\end{abstract}




\title{
Improving the Performance of \\ Photo-Electrically Controlled Lighting Systems
}

\author{
Francis Rubinstein \\ Gregory Ward \\ Rudy Verderber \\ Lawrence Berkeley Laboratory \\ Lighting Systems Research Group \\ Building 90, Room 3111 \\ Berkeley, CA 94720 \\ (415) 486-4096
}

\section{INTRODUCTION}

In buildings where daylight can serve as a useful source of illumination, photo-electrically controlled lighting systems can significantly reduce electric lighting requirements $[1,2,3,4]$. The goal of these systems is to supplement the available daylight at the task area with just enough electric light to meet the design level. Achieving this objective, th ugh, is complicated by the difference in the spatial distributions of daylight and electric light in the space as well as by the practical necessity of mounting the control photosensor in the ceiling rather than at the work surface [5].

In this paper, we describe the major components of a photo-electric dimming system and describe three simple control algorithms that can be incorporated into a control system. We then use experimental data from scale models to demonstrate how the control algorithm and the photosensor's geometry and location affect the ability of photo-electrically lighting systems to provide a specified illuminance level at the task.

\section{DESIGN AND OPERATION OF DAYLIGHTING CONTROLS}

The objective of a daylighting control system is to maintain a total light level at the task surface equal to the target design level with minimum use of electric lighting. While it may be difficult or impossible to precisely achieve this objective in practice, it is nevertheless a useful standard against which to compare the performance of existing daylighting control systems. Furthermore, this objective is also important with respect to building design and standards compliance since most building energy analysis models, including DOE-2, assume daylighting control systems that meet this objective. 


\section{System Components}

The photo-electrically controlled lighting systems we consider here consist of three basic components:

1. A photosensor for measuring the light level within or entering the controlled building space. The photosensor generates an electric signal in proportion to the illumination striking it. The particular geometry of the photocell and its housing determines the sensitivity of the cell to light from different directions. The photosensor is assumed to have a photopic spectral response.

2. A controller that incorporates an algorithm to process the signal from the photosensor and convert it to a command signal to the dimming unit.

3. A dimming unit that smoothly varies the light output of the electric lights by altering the amount of power flowing to the lamps.

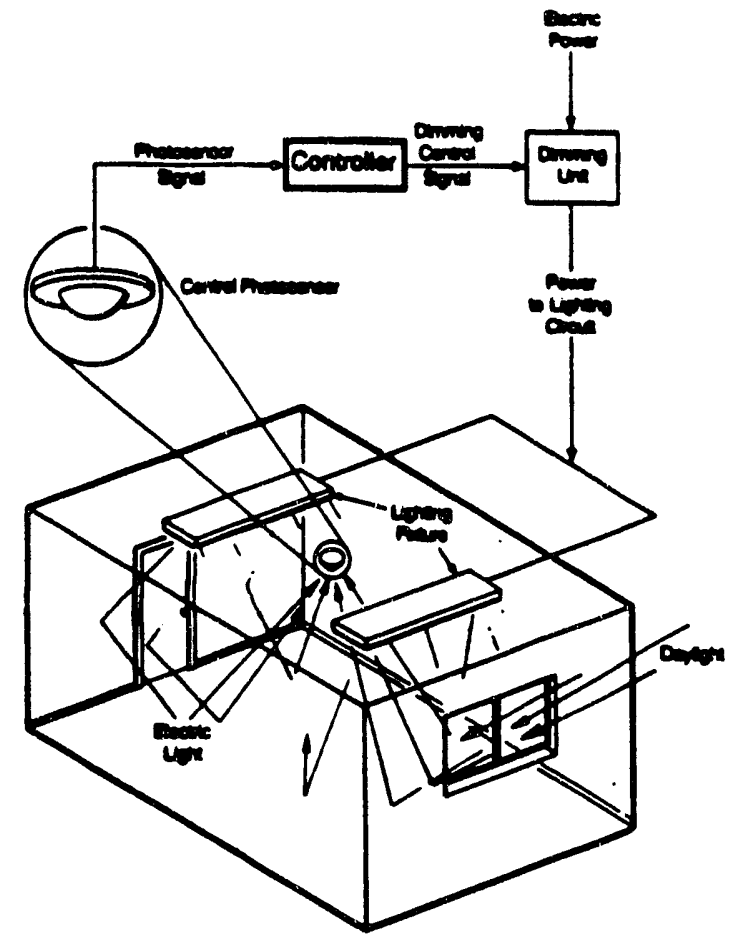

Figure 1. Graphical representation showing relationship between photoelectric dimming system components in typical daylighitng application. The ceiling-mounted control photosensor is sensitive to electric light within the space as well as daylight.

Figure 1 illustrates how these components are interconnected in a typical building application and also illustrates a typical mounting configuration for the control photosensor. The ceiling-mounted photosensor links the ambient light levels in the space (both electric and daylight) to the controller which, in turn adjusts the electric light output according to its 
built-in algorithm. Thus, the placement of the photosensor, the form of the control algorithm and their interaction largely determine how the system as a whole will perform.

\section{Design and Application Constraints}

There are a number of factors that constrain the design and application of photo-electric controls. The most important of these are:

1. The photosensor is usually mounted in the ceiling or on the exterior of the building face. Although placing the photosensor at the task would be ideal from an operational standpoint, a task-located sensor would be very susceptible to interference from the occupants and would be difficult to electrically connect to the rest of the control circuitry.

2. To reduce wiring costs, a minimal number of photocells should be used per control zone.

3. The system must be simple to install and calibrate after installation.

The first constraint is particularly important because the control objective is expressed in terms of the illuminance at the task surface (or work plane). Mounting the control photosensor in the ceiling pointing down towards the workplane rather than mounting it at the workplane pointing upwards introduces several difficulties. For example, a ceilingmounted photosensor doesn't directly measure the illuminance at the task. The best that can be hoped for is a photosensor signal that is approximately proportional to task illuminance. Regardless, the signal from the control photosensor is the only information available to the controller about the state of the lighting environment.

\section{Controller and Control Algorithms}

Although the control photosensor is the most visible part of a lighting control system, the controller plays a critical role by transforming the signal from the photosensor into a command signal for the dimming unit. The specific functional form of this transformation, which we term the control algorithm, is a circuit design consideration. If the algorithm used by the controller does not compensate for the fact that the control photosensor is generally mounted in the ceiling rather than at the task surface, then the daylighting control objective will not be satisfied.

There are three simple control algorithms that can be easily designed into a control system. We term these the a) integral reset, b) open-loop proportional and c) closed-loop proportional control algorithms. Each algorithm expresses a different relationship between the photosensor signal, $S_{T}$, and the output of the electric lights, $\delta$. These relationships are plotted in Figure 2. 


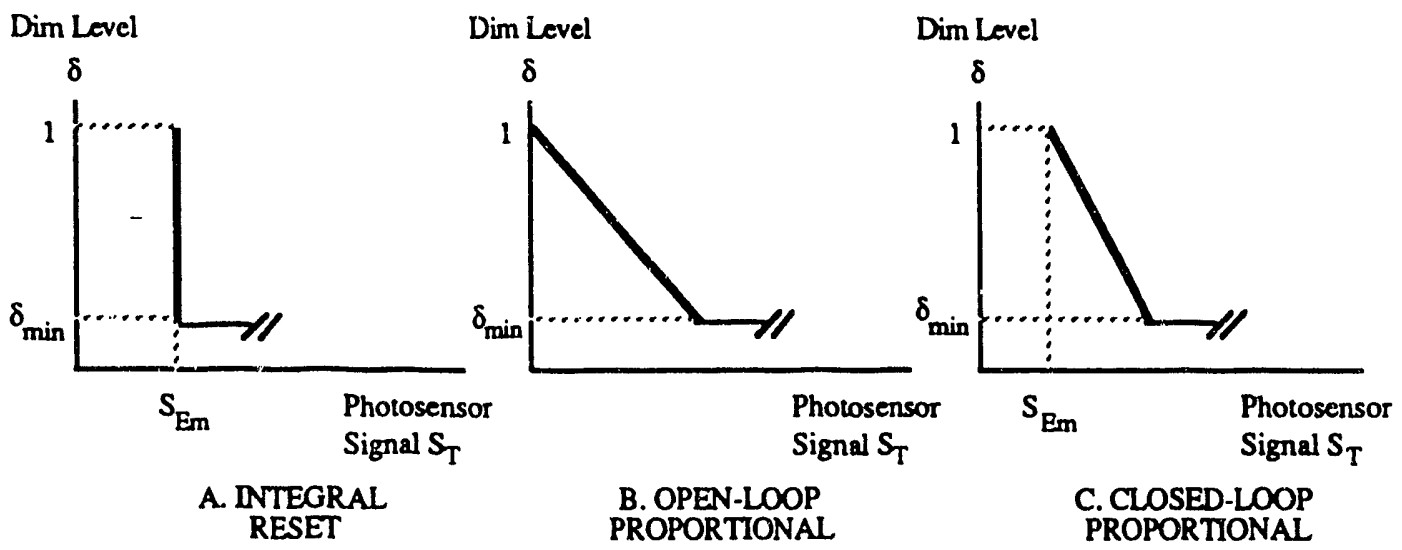

Figure 2. Plots showing relationship (transfer function) between total photosensor signal, ST, and fractional dimming level, $\delta$, for A) integral reset, B) open-loop proportional and C) closed-loop proportional control algorithms. The fractional dimming level can vary between $\delta_{\min }$ and 1 (full light output).

Integral reset and closed-loop proportional control algorithms are both considered to be closed-loop systems because the photosensor is located so that it can detect not only the independent quantity, daylight, but also the (controlled) electric light.

\section{Integral Reset}

Integral reset is the simplest control algorithm. An integral reset controller adjusts the dimming level $(\delta)$ so that the measured photosensor signal is kept at a constant reference level. In practice, this reference level is empirically determined by operating the electric lights at full intensity at night. (We refer to this process of adjusting the reference level at the site as the "night-time calibration"). The photosensor's output value under this condition $\left(\mathrm{S}_{\mathrm{Em}}\right)$ then becomes the reference level to be maintained under all conditions. As the photosensor detects, for example, an increase in light due to daylight, the controller reduces the electric light level to once again restore the photosensor signal to its reference value. Of course this algorithm only works if the photosensor can "see" the electric light it controls (closed-loop).

\section{Open-Loop Proportional}

With open-loop proportional control, the photosensor is mounted so that it does not detect the controlled quantity (electric light). Rather, the photosensor is used to detect solely the independent stimulus, daylight. The open-loop proportional control algorithm simply establishes a linear relationship between the detected photosensor signal and the dimming level. As the daylight stimulus exceeds zero, the electric lights dim along a line of slope $M$ as shown in Fig 2. (In the appendix, the value of the slope $M$ is shown to be equivalent to the scale factor or gain of an operational amplifier). By adjusting the value of the scale factor $M$ at an appropriate time during the day (what we call a "daytime calibration"), the 
installer sets the system sensitivity to accommodate the particular room and lighting conditions at that time. The daytime calibration need only be performed once for each control zone upon commissioning the lighting system.

\section{Closed-Loop Proportional Control}

With this type of control, the photocell should be located so that it operates in closed-loop mode (i.e. the photosensor should detect controlled electric light as well as daylight). But unlike integral reset, the photosensor signal is not kept constant. Rather, the controller adjusts the electric light output so that the dimming level, $\delta$, is a linear function of the difference between the photosensor signal and the night-time reference level. As with open-loop proportional control, a daytime calibration must be performed to adjust the system sensitivity so that the slope of the response ( $M$ in Fig. 2 ) is appropriate to the specific room and daylight conditions. The night-time reference level is determined by a nighttime calibration identical to that performed for an integral reset control.

By expressing each algorithm mathematically, we can derive expressions for the total light level at the task as a function of the daylight component of the photosensor signal and daylight on the task for each algorithm. Because there are three algorithms to consider, the formulation is necessarily lengthy. In the appendix, we present derivations and generic circuit diagrams for each algorithm.

Table 1 summarizes the appendix by presenting, for each algorithm, the algorithm's transfer function and an expression for task illuminance as a function of the daylight component of the photosensor signal as well as a conditional expression that must be satisfied to achieve the daylighting control objective. The definitions of the various terms used in the Appendix is also given in the table.

The transfer functions given in Table 1 express the relationship between the output of the photosensor and the dimming level, $\delta$, for each algorithm. (This relationship is expressed independently of $\delta$ for integral reset since the form of this simple algorithm is such that $\delta$ cannot be expressed functionally in terms of the photosensor signal). The expressions for total task illuminance are given in terms of $\mathrm{S}_{\mathrm{D}}(\mathrm{t})$, that fraction of the photosensor signal attributable only to daylight. It is convenient to express the task illuminance in terms of its daylight components because these are the independent quantities that can measured in scale models. However, it should be stressed that the controller only measures the total photosensor signal and has no way of differentiating between the electric light and daylight components. 
Table 1. Operational equations for different control algorithms (derivations in appendix).

\begin{tabular}{llll}
\hline Control Algorithm & \multicolumn{1}{c}{$\begin{array}{c}\text { Transfer } \\
\text { Function }\end{array}$} & $\begin{array}{c}\text { Task } \\
\text { Illuminance }\end{array}$ & $\begin{array}{c}\text { Conditional } \\
\text { Expression }\end{array}$ \\
\hline Integral Reset & $S_{T}(t)=S_{E m}$ & $L_{T}(t)=I_{D}(t)+I_{E m}\left(1-\frac{S_{D}(t)}{S_{E m}}\right)$ & $\frac{I_{D}(t)}{S_{D}(t)}=\frac{I_{E m}}{S_{E m}}$ \\
$\begin{array}{l}\text { Open-Loop } \\
\text { Proportional }\end{array}$ & $\delta=M S_{T}(t)+1$ & $\mathrm{~L}_{T}(t)=I_{D}(t)+I_{E m} \frac{M S_{D}(t)+1}{1-M S_{E m}}$ & $\frac{I_{D}(t)}{S_{D}(t)}=\frac{I_{D}\left(t_{c a l}\right)}{S_{D}\left(t_{c a l}\right)}$ \\
$\begin{array}{l}\text { Closed-Loop } \\
\text { Proportional }\end{array}$ & $\delta=M\left(S_{T}(t)-S_{E m}\right)+1$ & $I_{T}(t)=I_{D}(t)+I_{E m} \frac{1+M\left(S_{D}(t)-S_{E m}\right)}{1-M S_{E m}}$ & $\frac{I_{D}(t)}{S_{D}(t)}=\frac{I_{D}\left(t_{c a l}\right)}{S_{D}\left(t_{\text {atl }}\right)}$ \\
\hline
\end{tabular}

$S_{T}(t) \equiv$ signal produced by photosensor (time-dependent).

$S_{D}(t) \equiv$ daylight component of $S_{T}(t)$.

$S_{E}(t) \equiv$ electric light component of $S_{T}(t)$.

$\delta=$ fractional output of electric lights $(0 \leq \delta \leq 1)$. Full light output $\delta=1$, minimum light output $\delta=$ $\delta_{\min }$

$\mathrm{I}_{\mathrm{Em}}=$ task illuminance level for $\delta=1$ without daylight.

$\mathrm{S}_{\mathrm{Em}} \equiv$ signal produced by photosensor for $\delta=1$ without daylight.

$\mathrm{I}_{\mathrm{T}}(\mathrm{t})=$ total light at task (time-dependent).

$I_{D}(t) \equiv$ daylight at task (ime-dependent).

$I_{E}(t) \equiv$ electric light at task.

$I_{T}(t), I_{D}(t)$, and, $I_{E}(t)$ as defined above refer to the particular point or points on the workplane where the design objective is to be satisfied.

The conditional expressions given in the Table 1 describes the conditions that must be met if the daylighting control objective is to be achieved. From these expressions, it is apparent that all algorithms require that the ratio between the daylight component of the photosensor and daylight on the task surface, $I_{D}(t) / S_{D}(t)$, remain constant for all daylighting conditions. (For sake of brevity, the ratios $\mathrm{I}_{\mathrm{D}}(\mathrm{t}) / \mathrm{S}_{\mathrm{D}}(\mathrm{t})$ and $\mathrm{I}_{\mathrm{E}} / \mathrm{S}_{\mathrm{E}}$ are hereafter referred to as the tasksensor ratios for daylight and electric light, respectively). For an integral reset system, constant illumination on the task will only be achieved if the task-sensor ratio for daylight is equal to the task-sensor ratio for electric light. Open- and closed-loop proportional systems will only achieve the control objective if the task-sensor daylight ratio is always equal to the particular task-sensor daylight ratio obtained at time of daytime calibration $\left(t_{c}\right)$.

Given the above, we can determine how well a given control algorithm can achieve the control objective by measuring the daylight on the task and photosensor at various times 
throughout the day. In the following section, we describe a scale model used to obtain values of $S_{D}(t)$ and $I_{D}(t)$ under real sky and ground conditions.

\section{EXPERIMENTAL METHODS}

The objective of the experiments reported here was to measure the relationship between photosensor signal and daylight at the workplane in a scale model of typically daylighted spaces in order to investigate the ability of integral reset, and open- and closed-loop proportional control systems to meet the daylighting control objective.

\section{Physical Model Description}

A scale model was constructed to simulate two different room shapes - a small 15- $\mathrm{x} 15-\mathrm{ft}$ office with modestly sized window and a very long room of $30 \mathrm{ft}$ depth with the long dimension parallel to the window. The small office was modelled at 1:3 scale, while the long room was modelled at 1:6 scale.

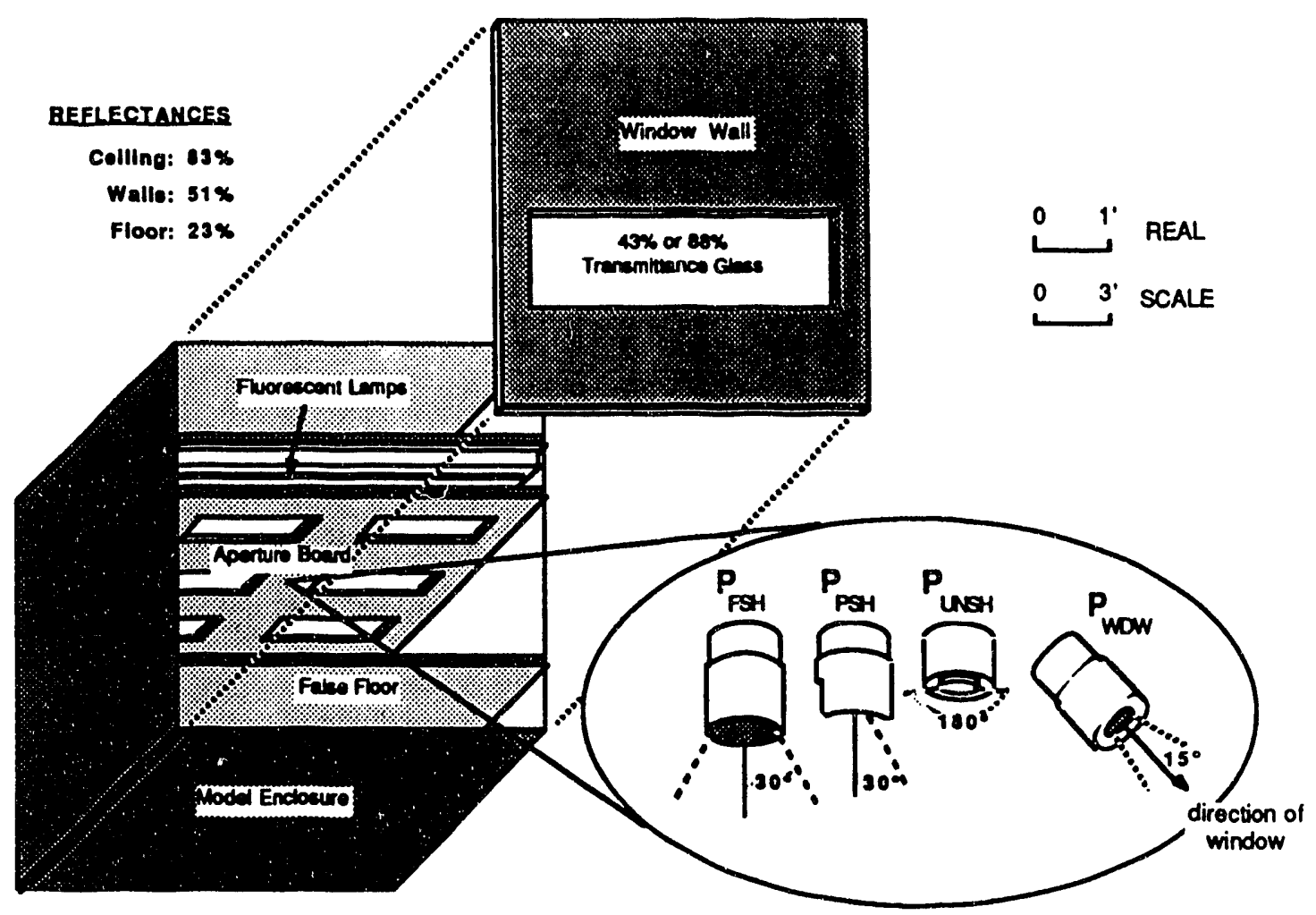

Figure 3. Exploded view of scale model of small office showing detailed view of the four ceiling-mounted control photosensors.

Figure 3 is an exploded view of the small office scale model. Figure 4 provides a similar view of the model configured as a very long room. By using mirrored surfaces as shown in Figure 4, we were able to model a room of effectively infinite length parallel to the 
window. The wall, ceiling and floor reflectances used for all the tests are indicated in the figures.

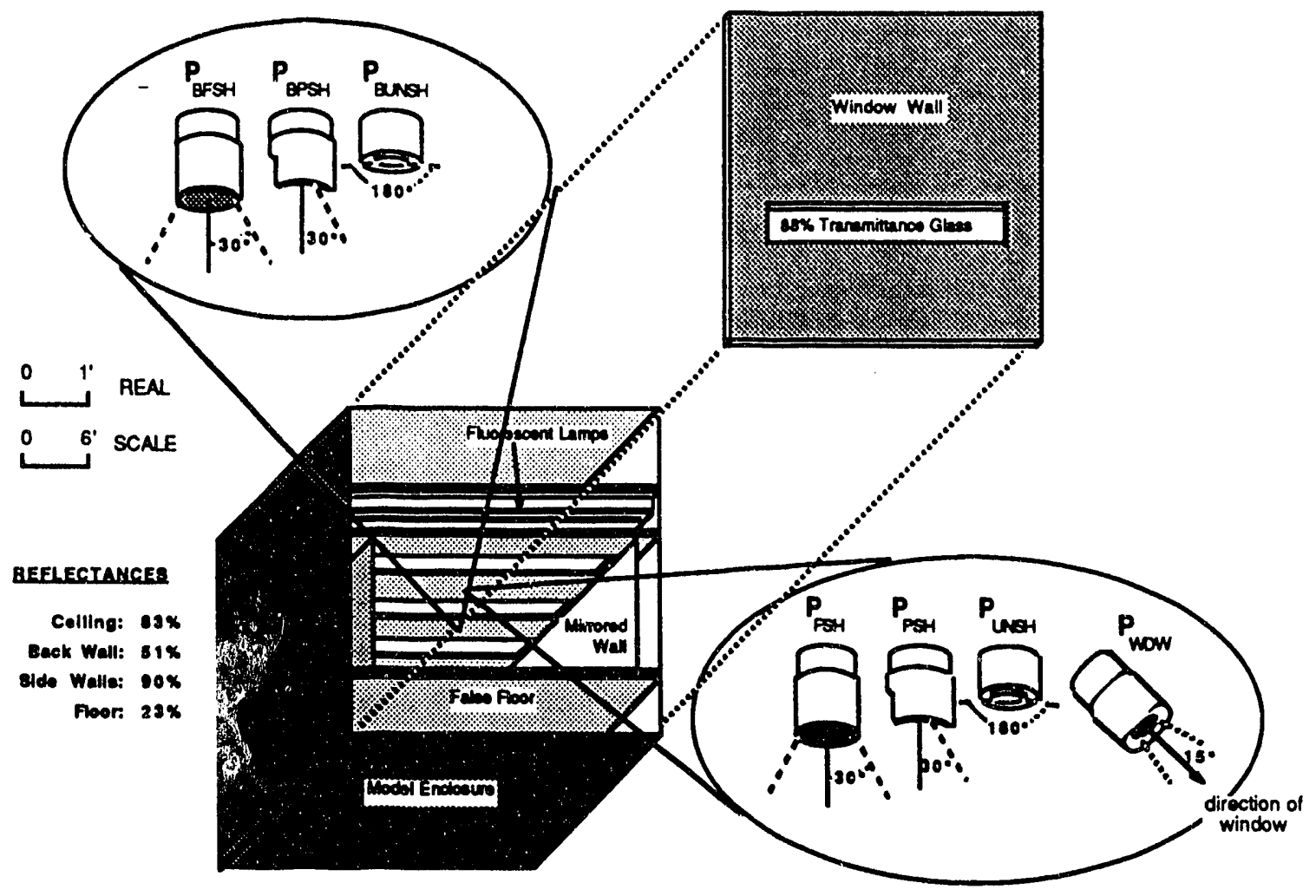

Figure 4. Exploded view of scale model of semi-infinite building space showing details of front and rear control photosensors.

The model could be rotated about a central pivot so that the window wall could be oriented towards any direction.

\section{Window System}

Since the window size and transmittance and the type of shading device used are the most important determinants of the quantity and distribution of daylight within the room, the window-wall of the model was removable, allowing testing of different fenestration strategies. For the single office model, we used a window with a 1:3 window-to-wall ratio (the ratio of the area of the window to the area of the entire window-wall as measured from inside the model room) and examined two types of glass: $43 \%$ and $88 \%$ transmittance (Fig. 3). For the semi-infinite room model, we used clear glass (88\% transmittance) with a window-to-wall ratio of 1:2 (Fig. 4).

Automatic Shading Device. During some of the tests, operable venetian blinds were used to prevent direct sunlight from entering into the model space. The venetian blind slats werc $3 / 4$ " wide and were a neutral gray color of approximately $50 \%$ reflectance. A small motor 
was employed to automatically control the blind blade angle. The motor was triggered by an external clock that incremented the blade angle by a given angle, either $10^{\circ}$ (Schedule $\mathrm{B}$ ) or $30^{\circ}$ (Schedule A), with each changing minute of the clock. This technique allowed us to test up to 10 different blade angles during a single day's test.

\section{Electric Lighting System}

The electric lighting system consisted of three two-lamp strip fixtures mounted to the underside of the fixture board with an aperture board below it (Figs. 3 and 4) to simulate the appearance and light distribution properties of a typical ceiling system. For the small office model, the aperture board consisted of six appropriately scaled rectangular apertures fitted with industry-standard prismatic lens material to simulate standard 2- $\mathrm{x}$ 4-ft fluorescent troffers (Fig. 5 and 3). For the semi-infinite room model, we simulated 3 continuous rows of fluorescent fixtures on 10 foot centers as shown in Figure 6 and 4.

\section{Instrumentation}

26 photometers were used to measure light both inside and outside the model. Most photometers were mounted at various positions in the work plane of the scale model for measuring illuminance. Other photometers were modified to simulate the spatial response characteristics of typical control photosensors.

\section{Control Photosensors}

In the small office model, we installed four modified photometers, designated $\mathrm{P}_{\text {unsh }}$ (unshielded), $P_{p s h}$ (partially-shielded), $P_{f s h}$ (fully-shielded), and $P_{w d w}$ (window-aimed) in the ceiling of the model for use as control photosensors (Fig. 3). The $\mathrm{P}_{\text {unsh }}$ photessensor was an unmodified, cosine-corrected photometer; consequently, the output from this photosensor was proportional to the ceiling illuminance. The $\mathrm{P}_{\mathrm{psh}}$ photosensor was equipped with an opaque baffle that shielded it from direct light from the window but otherwise allowed the photosensor a view of the floor and the three non-window-walls. The photosensor designated $\mathrm{P}_{\mathrm{fsh}}$ (fully-shielded) was fitted with a black-painted tube that restricted its field of view (FOV) to a cone of $30^{\circ}$ semi-angle allowing the sensor to detect light reflected from mosi of the floor while preventing it from directly detecting light from any of the four walls. The output of this photosensor was roughly proportional to the "avirage luminance" of the floor below. Finally, the $P_{w d w}$ photosensor (window-aimed) was equipped with a black tube that restricted the FOV to a cone of $15^{\circ}$ semi-angle. The photosensor was aimed at the center point of the window. The output of this sensor was related to the luminance of the ground plane outside the model and the luminance of the venetian blinds. Because this photosensor views only daylight, it could be used for openloop proportional control.

In the semi-infinite room model, an additional three photosensors were mounted in the ceiling as shown in Fig. 4. These additional photosensors, designated Pbunsh (back, unshielded), $P_{b p s h}$ (back, partially-shielded), and $P_{b f s h}$ (back, fully-shielded) were 
identical to their forward-mounted counterparts but were mounted further away from window. Using two clusters allows one to assess the importance of placing the ceiling mounted photosensors near the particular workplane locations where the control objective is to be satisfied.

\section{Workplane Photometers}

Sixteen cosine- and color-corrected photometers were installed in the small office model to measure the illuminance distribution at the work plane. As shown in Figure 5, these photometers were arranged in a regular $4 \times 4$ array on 16-in centers 10 inches above the floor. Since the small office model was scaled at $1: 3$, this height is equivalent to 30 inches where photometric measurements are typically made. The photometers were mounted to a framework painted the same color as the floor to minimize its effect on the light measurements.

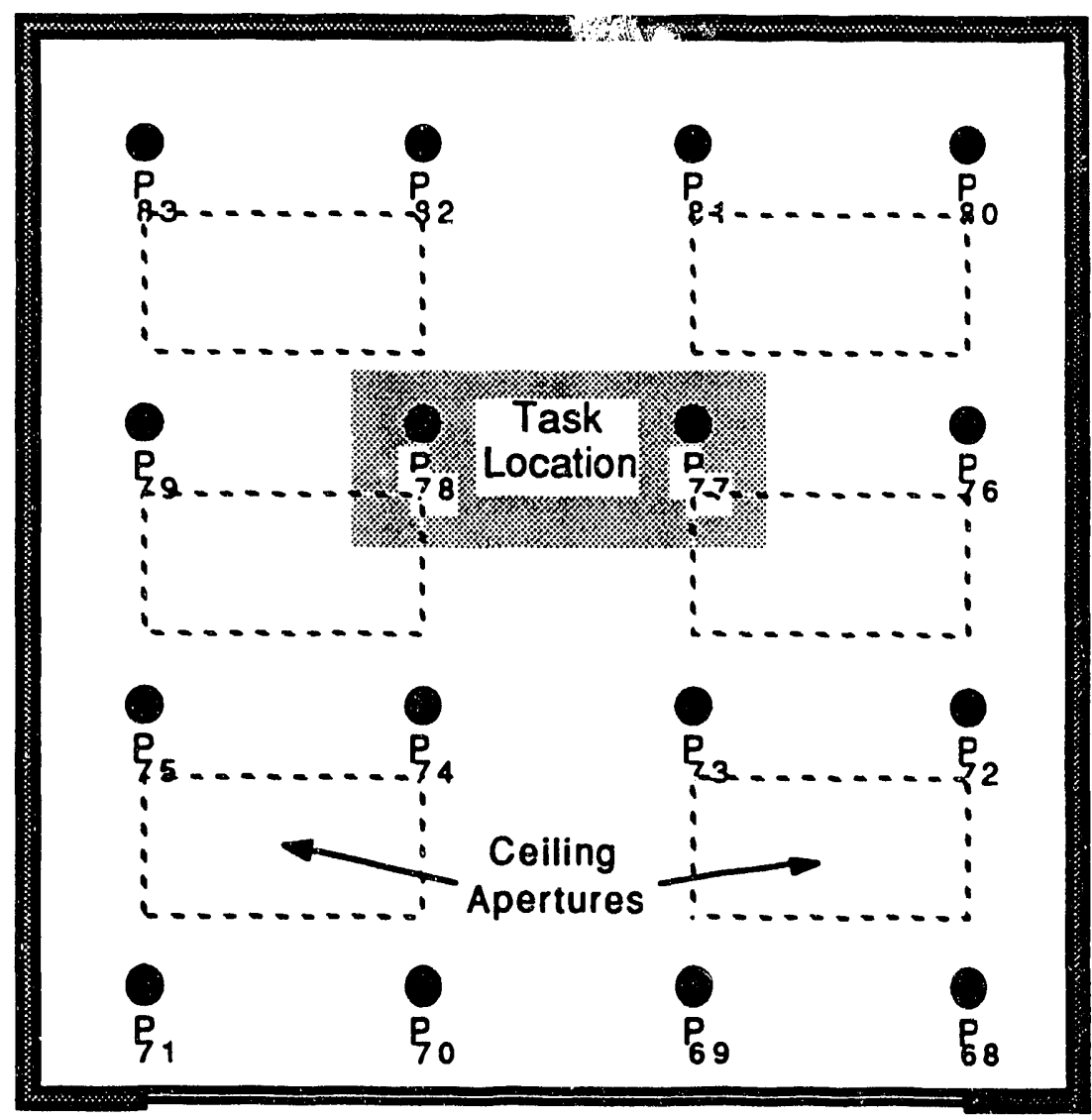

ALL WORKPLANE PHOTOMETERS

MOUNTED

AT 2.5 SCALE FEET ABOVE FLOOR

WINDOW

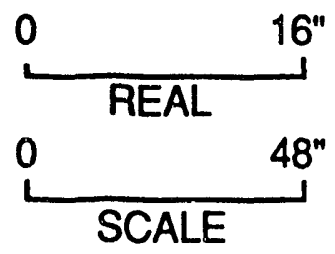

Figure 5. Floor plan and reflected ceiling diagram of small office model. The task illuminance was considered to be the average of the illuminances measured at station points $\mathrm{P}_{77}$ and $\mathrm{P}_{78 .}$ 
For the semi-infinite room model, we used a linear array of fifteen photometers for measuring the workplane illumination with the photometers oriented with respect to the window as shown in Fig. 6. (Because of the side wall mirrors used to simulate the infinite room length parallel to the window, it can be shown that only measurements along the room centerline are meaningful in this context).

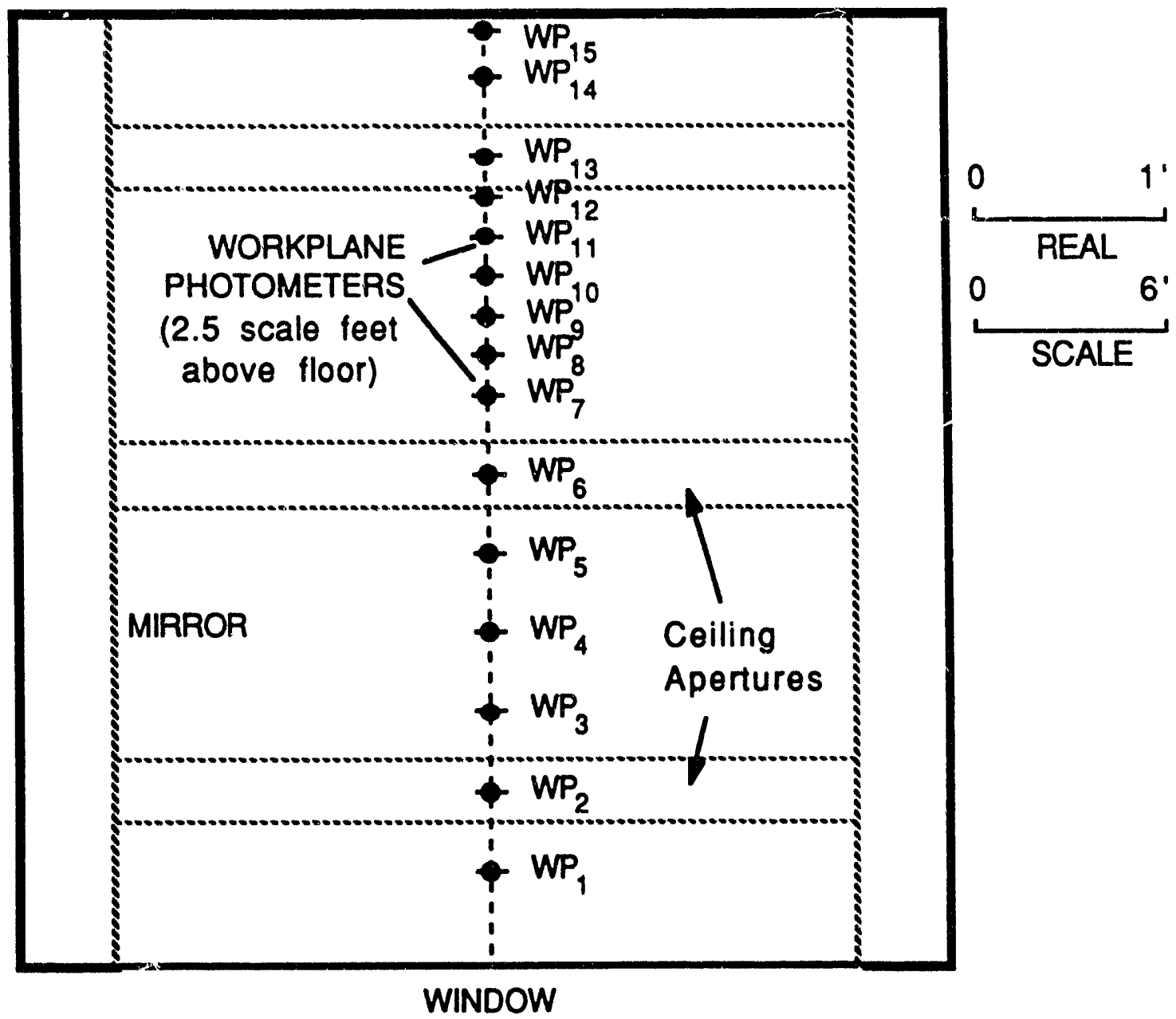

Figure 6. Floor plan and reflected ceiling diagram of semi-infinite room. The illuminance measured at station point WP4 was used to indicale the illuminance of the front of the room. The measurement from WP9 was used for the illuminance of the rear of the room.

\section{Test Site Description}

The scale model was located on the roof of the third floor roof of Building 90 at Lawrence Berkeley Laboratory. The model was anchored to a wood deck of $20-40 \%$ reflectance. The model had an unobstructed view of the sky when aimed in the west or south directions. Towards the east, the tops of three evergreen trees obstructed part of the sky. As shown in 
Figure 7, the foursih floor blocked much of the view north while the Berkeley hills that run NW to SE behind the building block additional portions of the sky to the north and east.

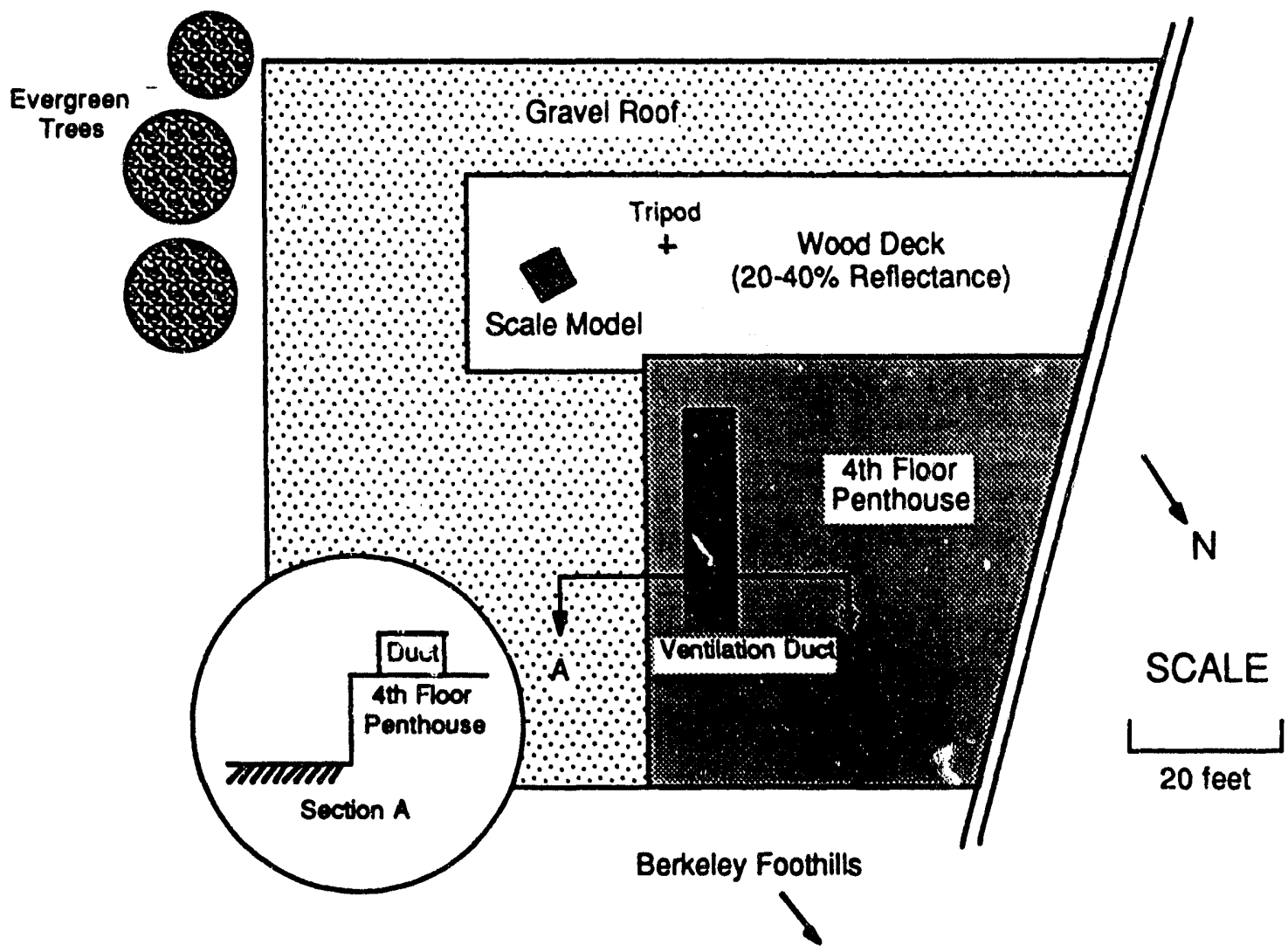

Figure 7. Diagram showing location of scale model test site.

\section{Testing Procedures}

Between Februsry, 1984 and January, 1987 data were taken periodically for two to five days at a time, deprending on weather conditions. Before a test, the model was pointed in a particular direction (i.e., north, east, south or west) and the data acquisition system programmed to take data scans at regular intervals (typically once every five minutes). With the electric lights off, the outputs of all the workplane photometers and control photosensors were rapidly read and recorded (in less than 2 seconds). Each scan therefore yielded simultaneous measurements of $\mathrm{S}_{\mathrm{D}}{ }^{\dagger}$ for all photosensors and $\mathrm{I}_{\mathrm{D}}$ for all workplane photometers. After from two to five days, the data acquisition system was stopped and the model rotated to another direction for the next round of data collection. Occasionally, all photosensor and photometers were read at night with the electric lights on full to establish the values of $S_{E m}$ and $I_{E m}$ for the model's electric lighting system.

t We use $S_{D}$ to indicate a particular measurement of the daylight component of the photosensor signal as oppcsed to $S_{D}(t)$, which refers to all possible values. 


\section{Task Locations and Design Light Levels}

Our analysis assumes that there is a point or points on the workplane where we want maintain a specified task illuminance level. For the small office model, we assumed a task located approximately $2 / 3$ of the way in from the window as shown in Figure 5. We took the task illiminance to be the average illuminance measured at the station points $\mathrm{WP}_{77}$ and $\mathrm{WP}_{78}, \mathrm{~h}$ are symmetrically located about the room centerline as indicated. For the semi-infinite room case, we took the task illuminance of the front portion of the room to be the light measured at station point $\mathrm{WP}_{4}$ and the illuminance of the rear to be the light measured at WP9 as shown in Fig 6.

The target light level for the small office model was 720 lux. In the semi-infinite room, the target light level was 717 iux at the front station point $\mathrm{WP}_{4}$ and 736 lux at the rear station point WP9. These target light levels are the light levels measured at night with the electric lights on full.

\section{RESULTS}

\section{Correlations Between Task Iluminance and Photosensor Signal}

\section{Small Office Model}

The relationships between daylight at the selected workplane point and the output of the indicated ceiling-mounted control photosensor are presented as scatter plots for typical clear days for the small office model pointing west in rig. 8. The left column of plots (A, C, E, and $G$ ) is data for a clear summer day with no blinds installed in the model. The right column (B, D, F and $\mathrm{H})$ is for a clear summer and winter day with operable blinds installed. In the "no blinds" scatter plots, we have excluded data points collected when the sun was within $90^{\circ}$ from normal to the window. Similarly, for the model equipped with the operable blinds, we computationally excluded those data points for which the blade angle was such as to allow direct solar penetration. This treatment is justifiable because, in any realistic building application, direct sun would be excluded by appropriate window treatment.

For an ideal photosensor, all the points in the scatter plot would all lie along a line. While such ideal behavior was not exhibited by any of the photosensors we examined, the scatter plots for the partially-shielded and fully-shielded sensors are both fairly linear and show relatively little scatter. This is in contrast to the window-aimed photosensor and, to a lesser extent, the unshielded photosensor which show poorer correlation between the photosensor signal and workplane illuminance.

Table 2 presents statistics that summarize the degree of correlation between the measured workplane illuminance values, $I_{D}$, and the measured photosensor signal, $S_{D}$, for each control photosensor and for all directions, including the west data shown in Fig. 8. The slope of the line that best fits the data sets for each day and photosensor was determined by 


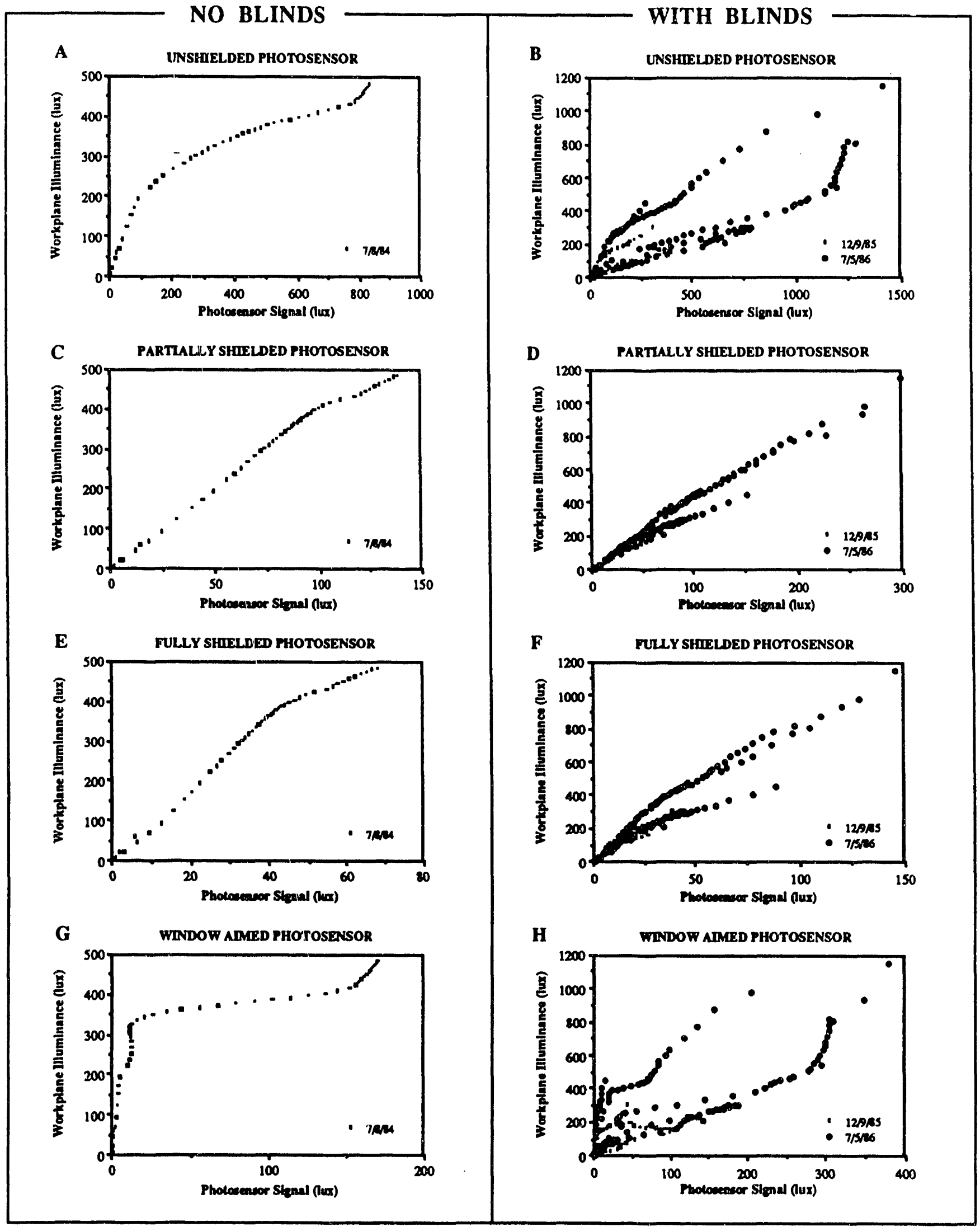

Figure 8. Scatter plots of daylight on control photosensors vs average daylight at WP77 and WP78 station points for small office model facing west with and without shading device. Data points representing direct sclar penetration into interior space 


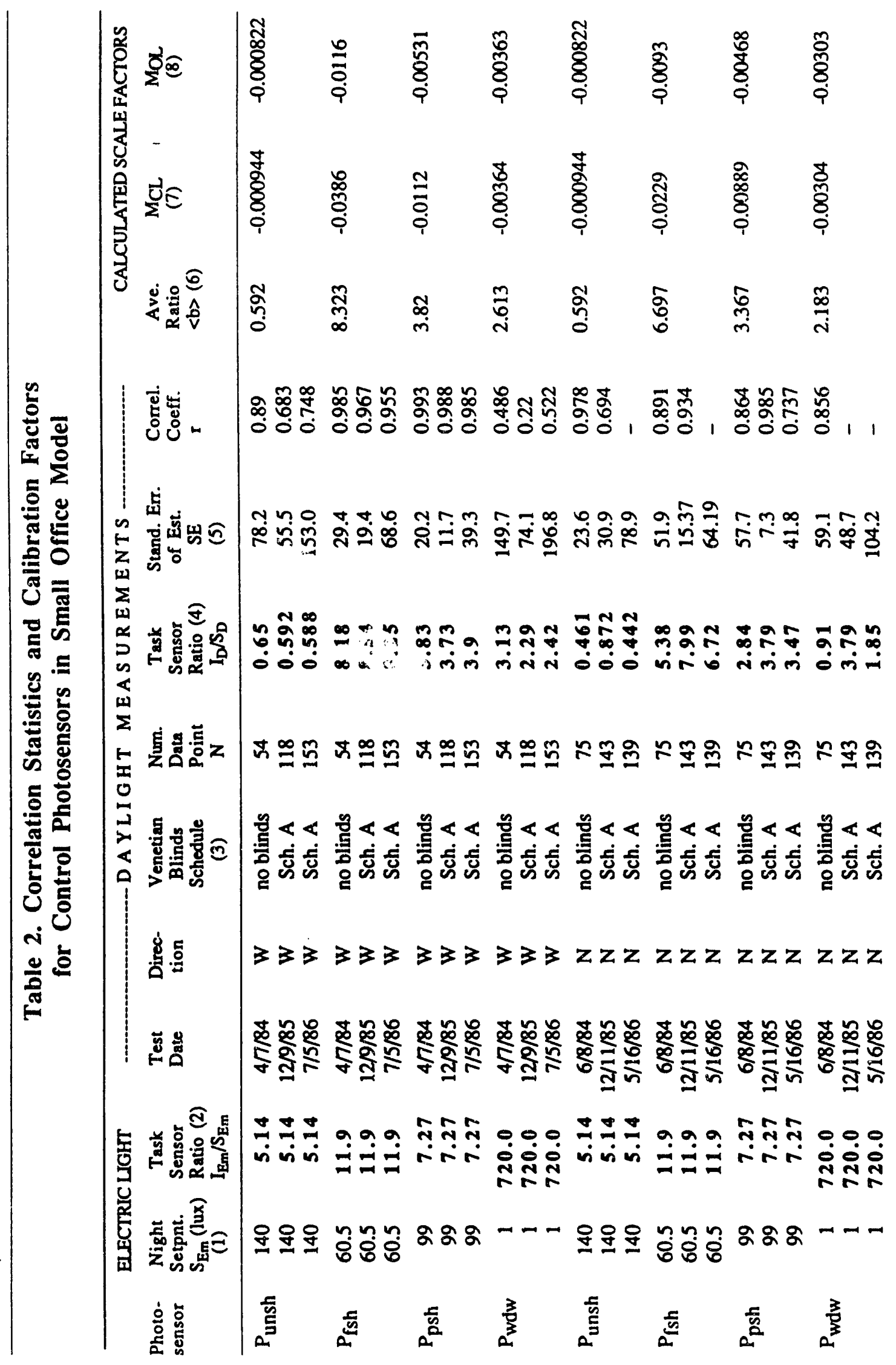




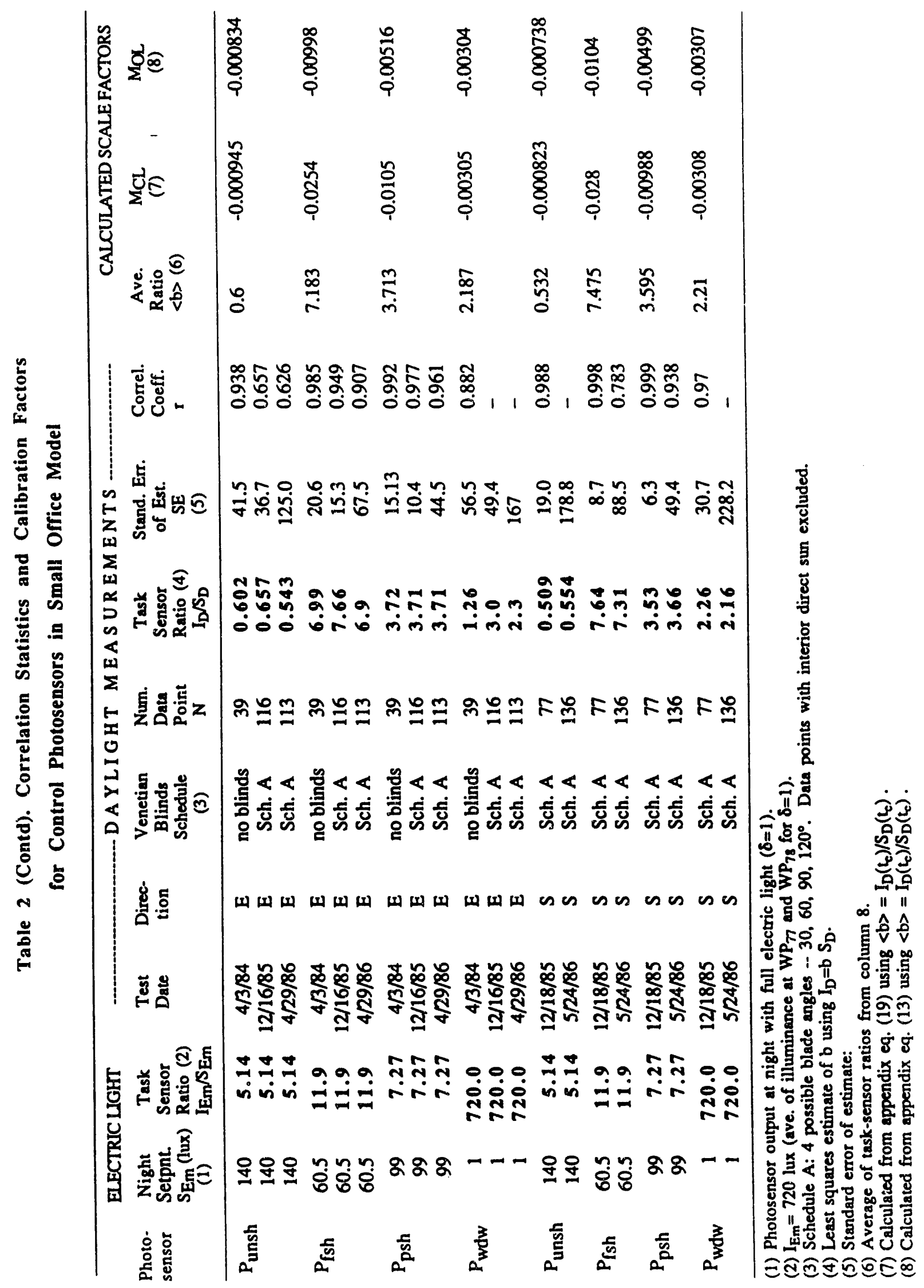


applying a least-squares fit to the data using $I_{D}=b S_{D}$ and solving for the coefficient $b$. We use $b$ as our best estimate of the generalized task-sensor daylight ratio $I_{D}(t) / S_{D}(t)$ for each test day and photosensor. The standard error of the estimate (SE) and correlation coefficient ( $r$ ) are measures of how well each data set can be fitted to a line with slope $b$ passing through the origin. For a perfect fit, SE should be 0 and $r$ should be 1 .

By comparing the task-sensor electric light ratios $\left(\mathrm{I}_{\mathrm{Em}} / \mathrm{S}_{\mathrm{Em}}\right)$ to the values of $b$, it is clear that the data is not in good agreement with the conditional expression given in Table 1 for integral-reset daylight control. For all photosensors, the task-sensor electric light ratios exceed the daylight ratios. For the unshielded photosensor, the electric light ratio is roughly 10 times the daylight ratios. Less extreme differences are seen for the fully- and partially-shielded photosensors.

As previously discussed, the daylight workplane illuminance and the output of the control photosensor must be well correlated to satisfy the daylighting control objective. While the details of the data vary depending on the direction and photosensor, several major trends are evident from Table 2. Except for the north-facing window, the signal from partially shielded photosensor, $\mathrm{P}_{\mathrm{psh}}$, was best correlated with the illuminance at the workplane as evidenced by the high values of $r$ and low values of the standard error. Furthermore, the fitted value of the slope $b$ was consistent between the winter and summer days regardless of the presence or absence of the venetian blinds. Using the same criteria, the fully shielded photosensor, $\mathrm{P}_{\mathrm{fsh}}$, also performs reasonably well but consistently ranked lower than $\mathrm{P}_{\mathrm{psh}}$.

Compared to $\mathrm{P}_{\mathrm{psh}}$ or $\mathrm{P}_{\mathrm{fsh}}$, the high standard errors for the unshielded photosensor, $\mathrm{P}_{\text {unsh, }}$ indicate poorer correlation between photosensor output and workplane illuminance. Note that the valse of $\mathrm{r}$ for the unshielded photosensor is particularly low (and SE relatively high) in the model with venetian blinds indicating that the task-sensor ratio for this sensor are strongly affected by venetian blind blade angle.

The data on the response for the window aimed photosensor, $\mathrm{P}_{\mathrm{wdw}}$, show that the output of this photosensor is a poor indicator of the illuminance at the workplane. The relationship between sensor output and workplane illuminance is highly sensitive to the season and blade angle. For most orientations, the r's are so low that one cannot reject the hypothesis that there is no correlation between workplane illuminance and photosensor output.

\section{Semi Infinite Room Model}

The relationship between workplane illuminance and photosensor signal on a clear winter day are shown as scatter plots in Fig. 9 for the west-aimed model fitted with clear window and operable blind system. The plots in the left-hand column of Fig. 9 show the relationship between the front cluster photosensors (Fig. 4) and the daylight workplane illuminance at the $\mathrm{WP}_{4}$ station point (Fig. 6). The right hand plots show the equivalent 


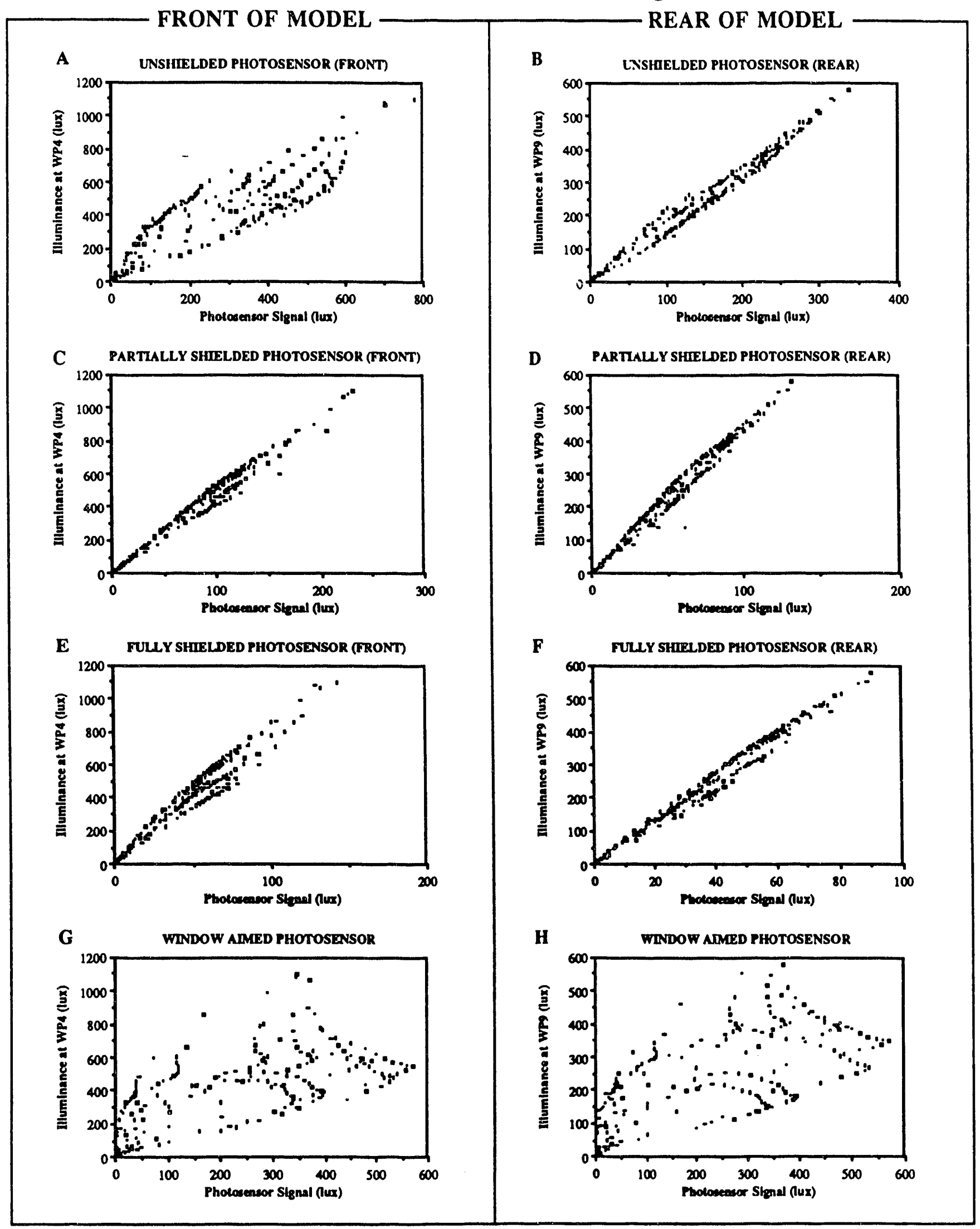

Figure 9. Scatter plots of daylight on control photosensors vs daylight on workplane (front and rear of model) for semiinfinite room model facing west with shading device on clear, winter day. Data points representing direct solar penetration into interior space are excluded. 


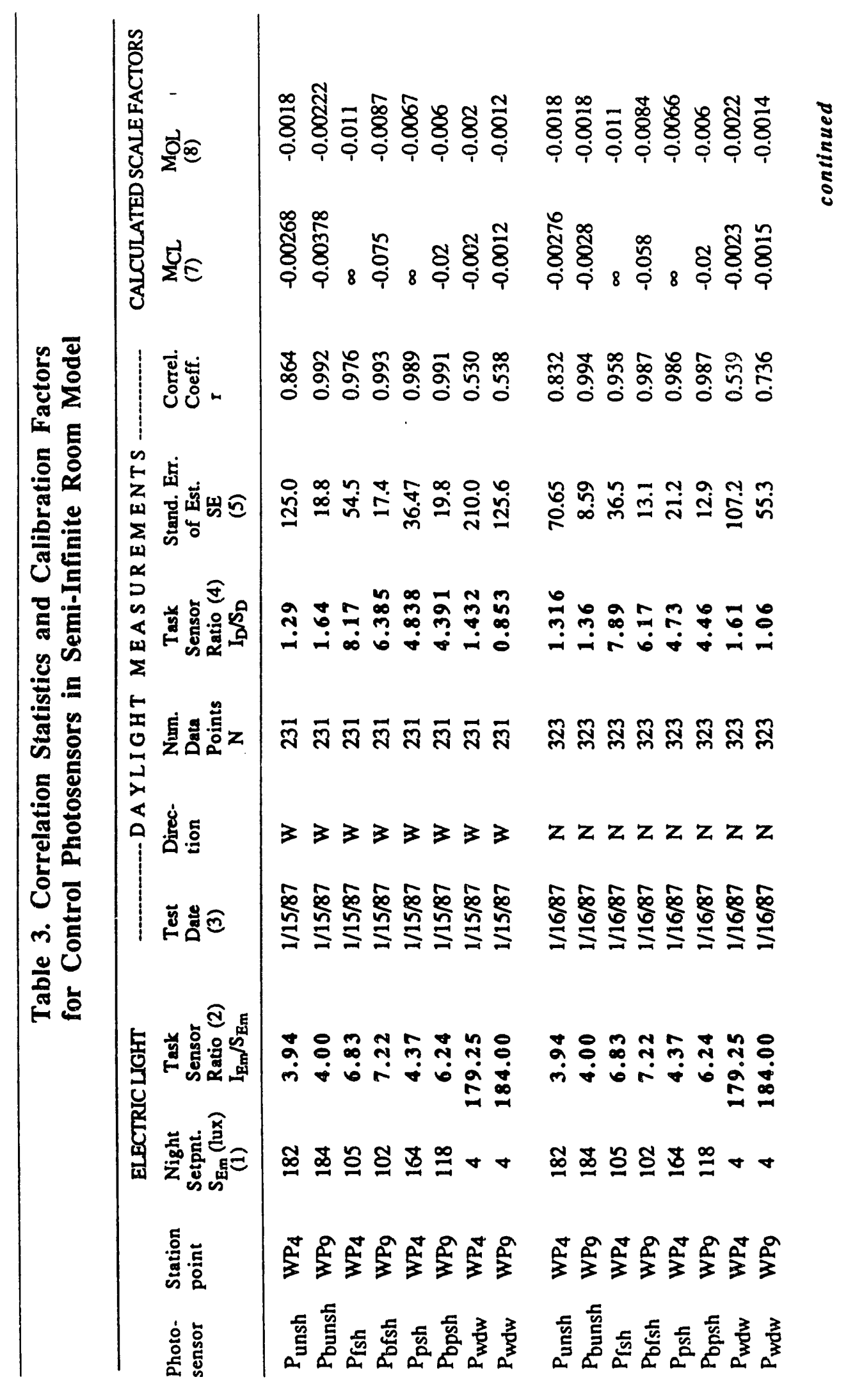




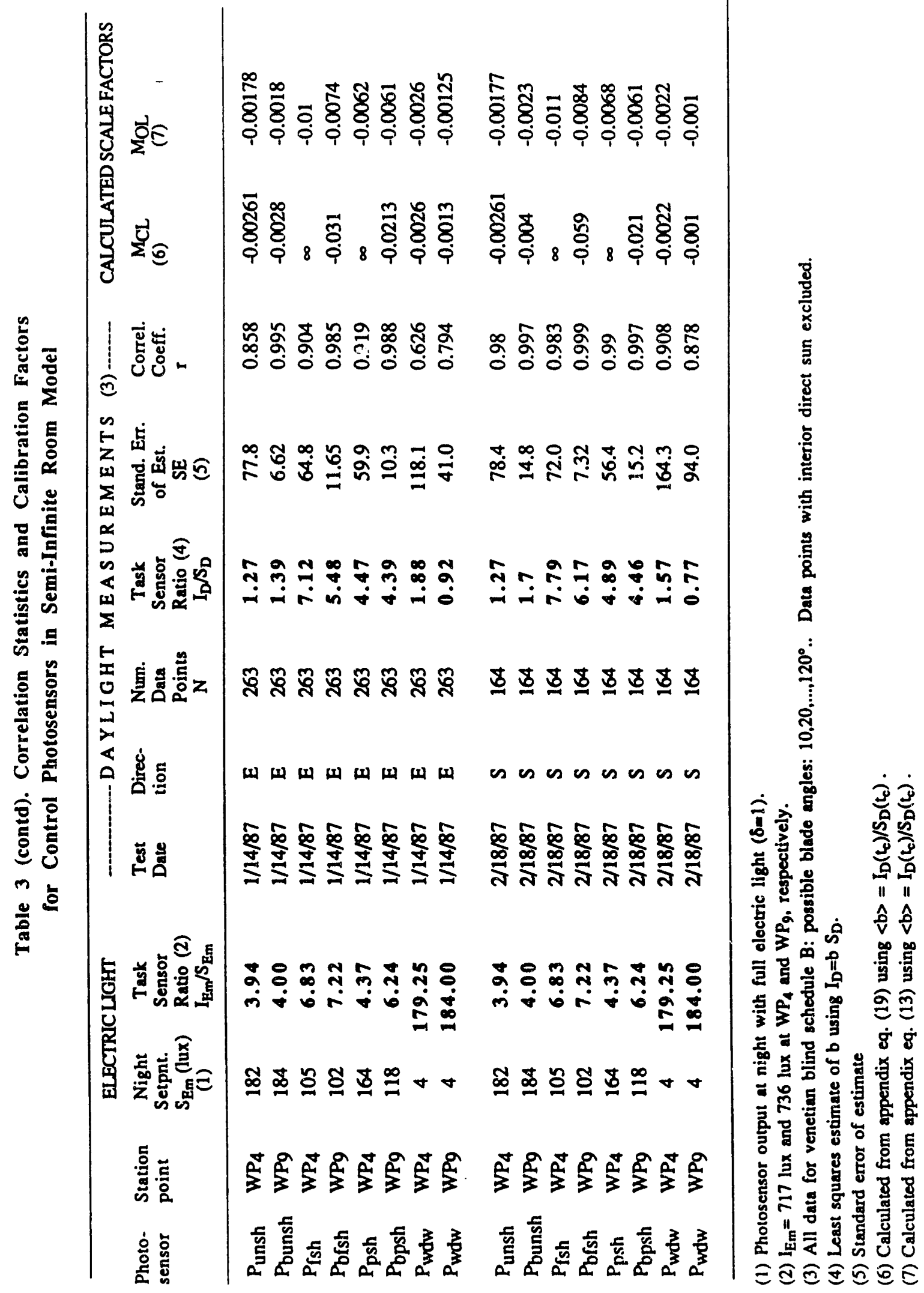


relationships between the rear photosensors and the $\mathrm{WP}_{9}$ station point (Fig. 6). In these scatter plots, we have excluded data points that occurred when the blade angles were such that direct sun penetrated into the model interior.

Table 3 strmmarizes the best-line slopes, goodness of fit and standard errors statistics for the scatter plots given in Fig. 9 as well as for the other directions.

Qualitatively, in the front portion of the model, the correlations between the various control photosensors and workplane illuminance rank similarly as in the small office model.

Photosensor output and workplane illuminance are best correlated for the partially shielded photosensor while there is poor correlation for the window-aimed photosensor. In the rear portion of the model, though, the unshielded photosensor performs generally as well, and for some orientations, better than the partially or fully shielded photosensors.

In the front portion of the model, the task-sensor daylight ratios for the partially-shielded photosensor (as estimated by b) are roughly equal to, while the fully-shielded photosensor actually exceed, the electric light ratios. For the rear portion of the model, the values of $b$ are lower than the electric light ratios for all photosensors, similar to the small office model.

\section{Task Illuminance for Various Control Algorithms}

To show how the electric light levels supplied by a photo-electric control system are affected by the control algorithm, we have used the expressions for task illuminance given in Table 1 with a subset of measured values of $S_{D}$ and $I_{D}$ from the west data summarized in Tables 2 and 3. The validity of simulating the task illuminance levels based on measured model data has been demonstrated in [6] by comparing the simulated results with measured data from physically constructed control circuits.

\section{Integral Reset}

The total task illuminance is plotted as a function of time of day for the $P_{u n s h}, P_{p s h}$, and $P_{\mathrm{fsh}}$ photosensors driving integral-reset control systems in the left column of Figs 10 (for winter) and 11 (for summer) for the small office model facing west. Analogous results for the front and rear portion of the semi-infinite room are given for winter only in Fig. 12 and 13 , respectively.

The grey shaded area in each graph shows the contribution of daylight to the total illuminance at the indicated workplane point(s) as a function of time of day for the particular test day. The cross-hatched area shows the contribution of supplied electric light to the workplane illuminance for the indicated control photosensor and algorithm. The upper boundary of the cross-hatched area is the total illuminance at the task. In each graph, the dashed curve gives the blade angle of venetian blind system as a function of time of day. The blade angles shown are those slat angles that excluded direct sun from penetrating the model while permitting maximum slat openness. We selected this venetian blind control strategy for the small office model to mimic the way the room occupant might use 


\section{Small Office Model, West, Clear Winter Day}

A.

INTEGRAL RESET CONTROL FROM UNSHIELDED SENSOR

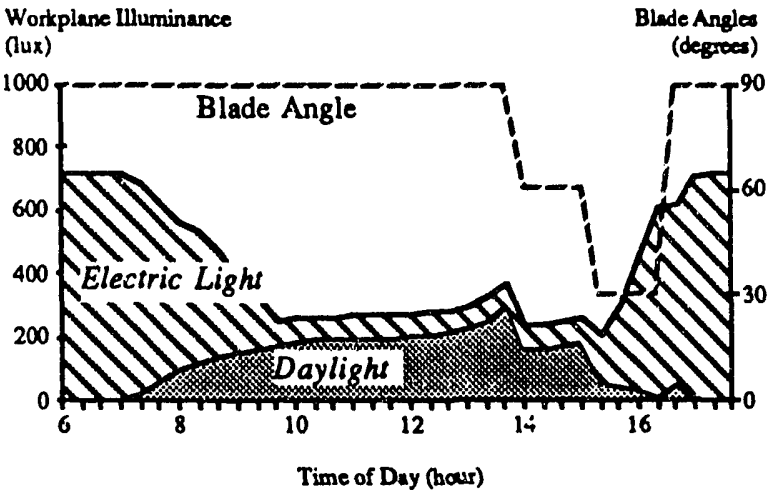

C. INTEGRAL RESET CONTROL FROM PARTIALLY SHIELDED SENSOR

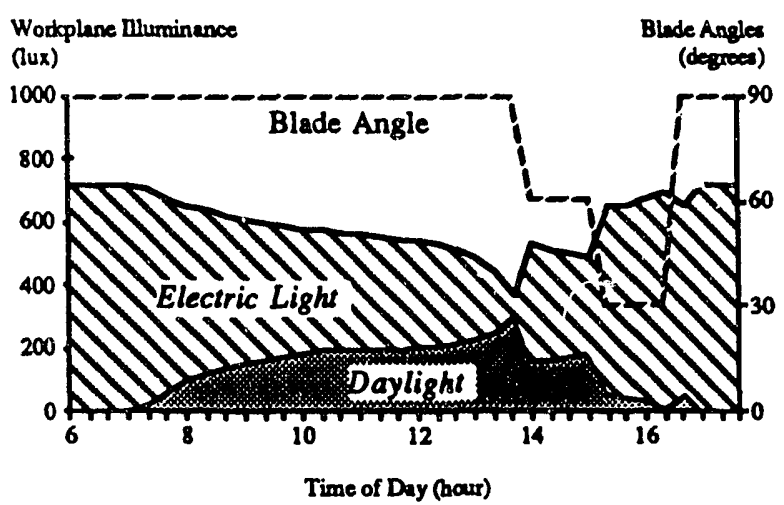

E. INTEGRAL RESET CONTROL FROM FULLY SHIELDED SENSOR

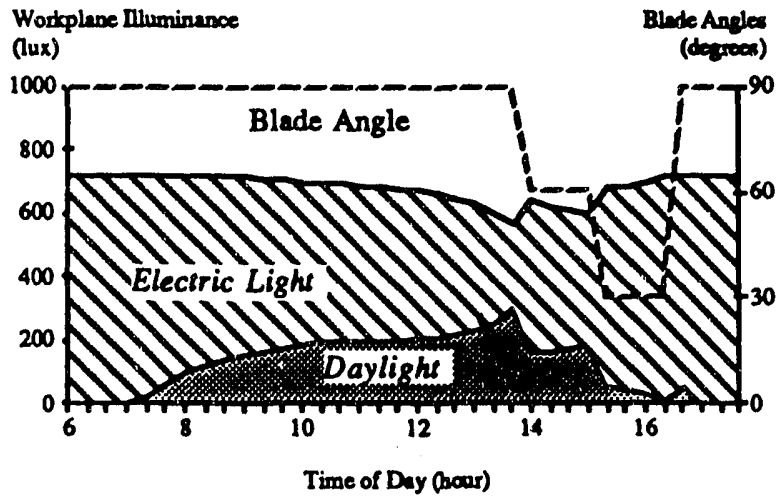

B . PROPORTIONAL CONTROL FRCM UNSHIELDED SENSOR

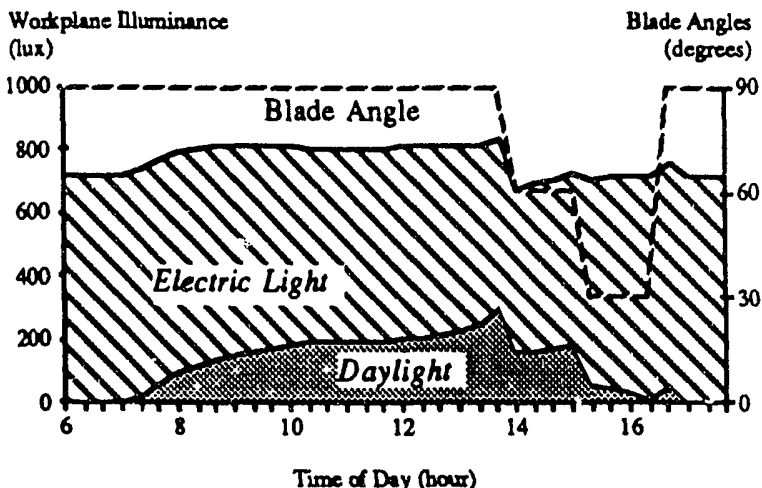

D. PROPORTIONAL CONTROL FROM PARTIALLY SHIELDED SENSOR

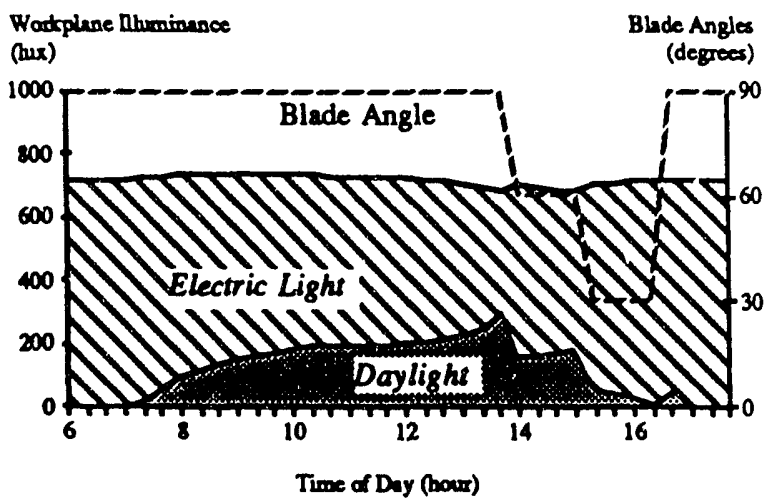

F. PROPORTIONAL COIITROL FROM FULLY SHIEIDED SENSOR

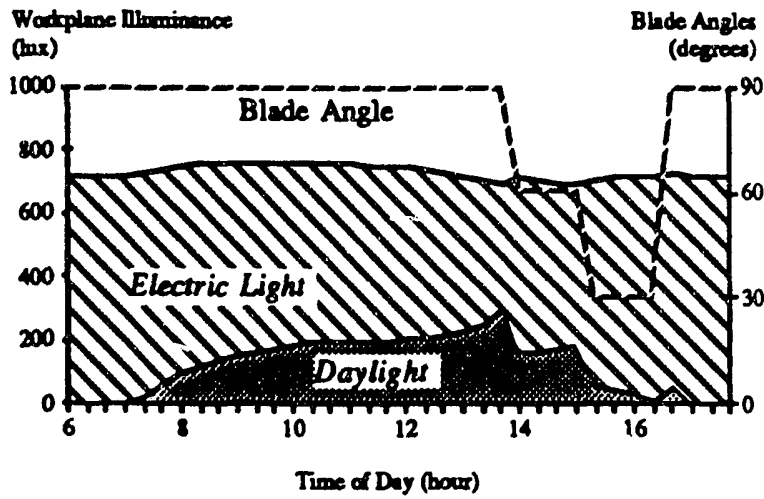

Figure 10. Light levels on workplane for integral reset and closed-loop proportional control systems controlled by three photosensors for small office model facing west on clear winter day (12/9/85). Target light level is 720 lux. 


\section{Small Office Model, West, Clear Summer Day}

A .

INTEGRAL RESET CONTROL FROM UNSHIELDED SENSOR

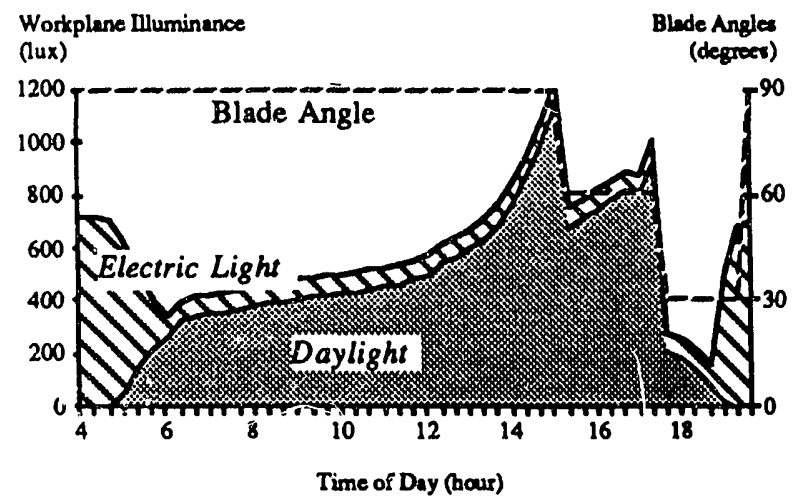

C. INTEGRAL RESET CONTROL FROM PARTIALLY SHIELDED SENSOR

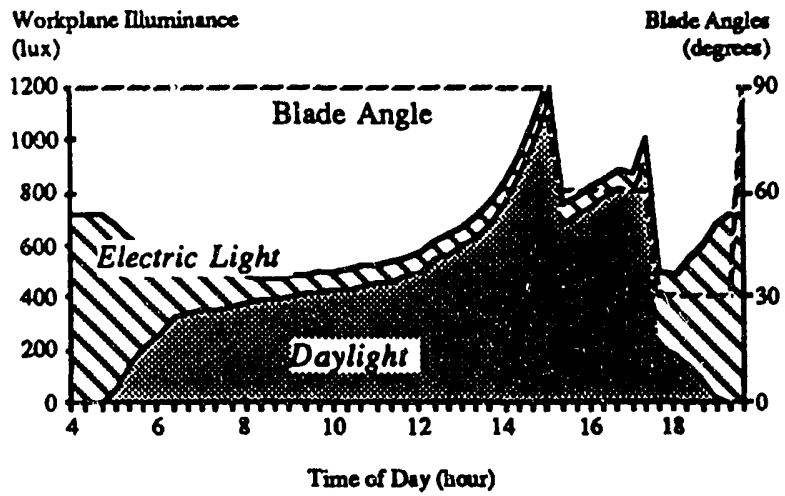

E. INTEGRAL RESET CONTROL FROM FULLY SHIELDED SENSOR

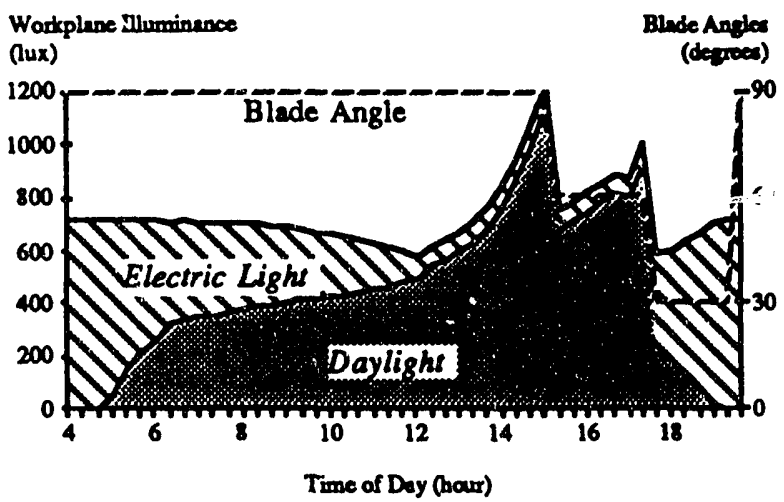

B . PROPORTIONAL CONTROL FROM UNSHIELDED SENSOR

Workplane Iliuminance
(lux)

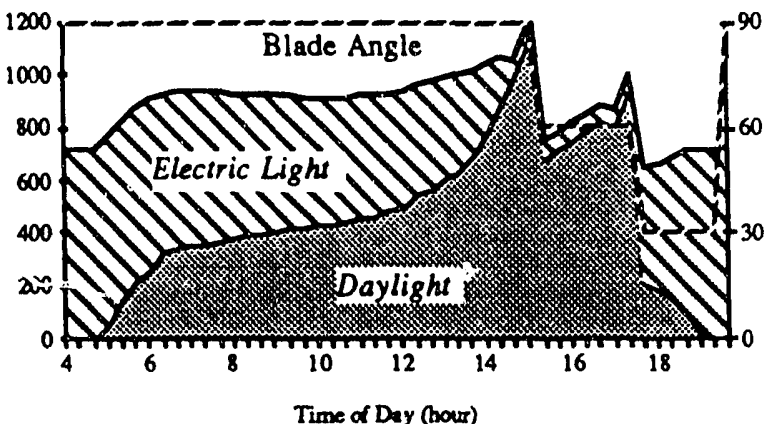

D. PROPORTIONAL CONTROL FROM PARTIALLY SHIELDED SENSOR

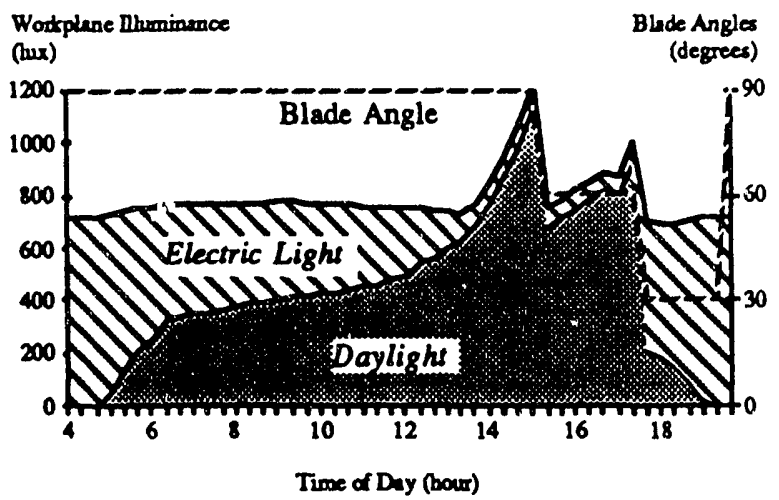

F. PROPORTIONAL CONTROL FROM FULLY SHIELDED SENSOR

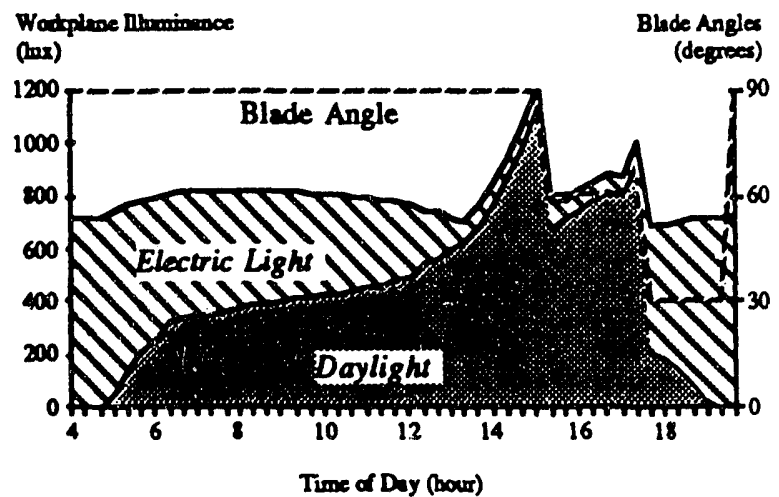

Figure 11. Light levels on workplane for integral reset and closed-loop proportional control systems controlled by three photosensors for small office model facing west on clear summer day (7/5/86). Target light level is 720 lux. 


\section{: Front of Semi-Infinite Room Model, West, Clear Winter Day}

A. INTEGRAL RESET CONTROL FROM FRONT UNSHIELDED SENSOR

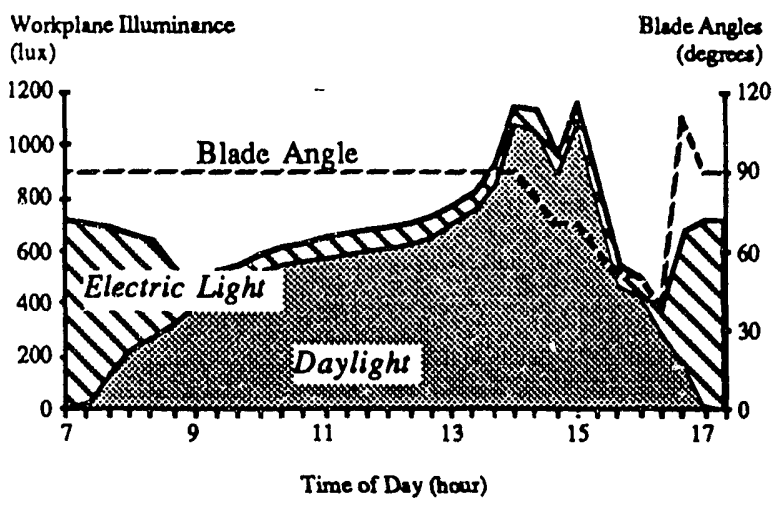

C. INTEGRAL RESET CONIROL FROM FRONT PARTIALIY SHIELDED SENSOR

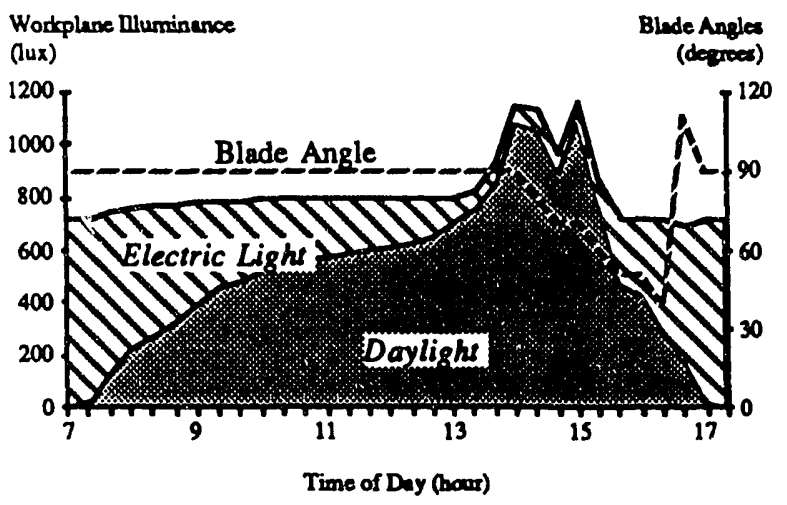

E. INTEGRAL RESET CONTROL FROM FRONT FULLY SHIELDED SENSOR

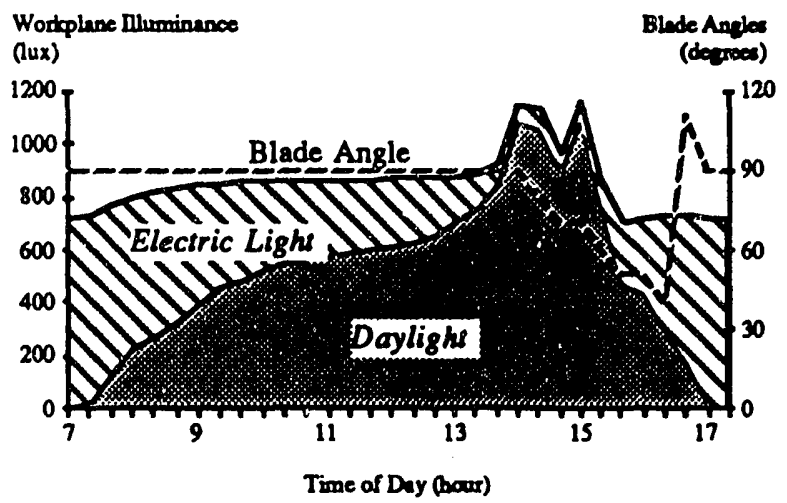

B . PROPORTIONAL CONTROL FROM FRONT UNSHIELDED SENSOR

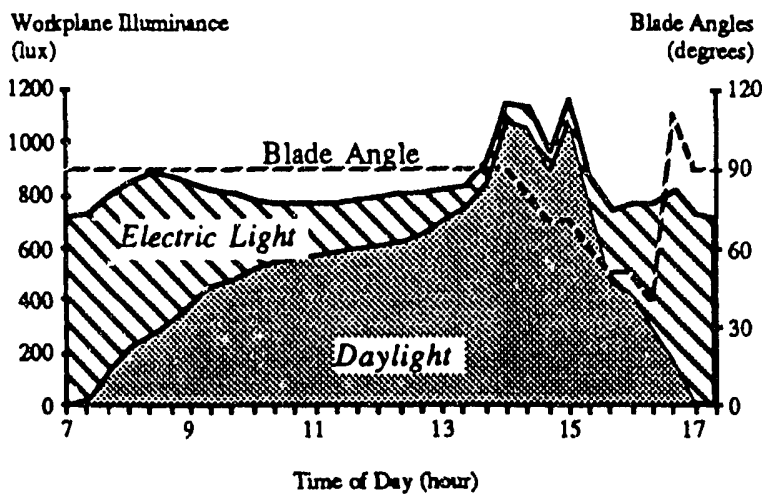

D. PROPORTIONAL CONTROL FROM FRONT PARTIALLY SHIELDED SENSOR

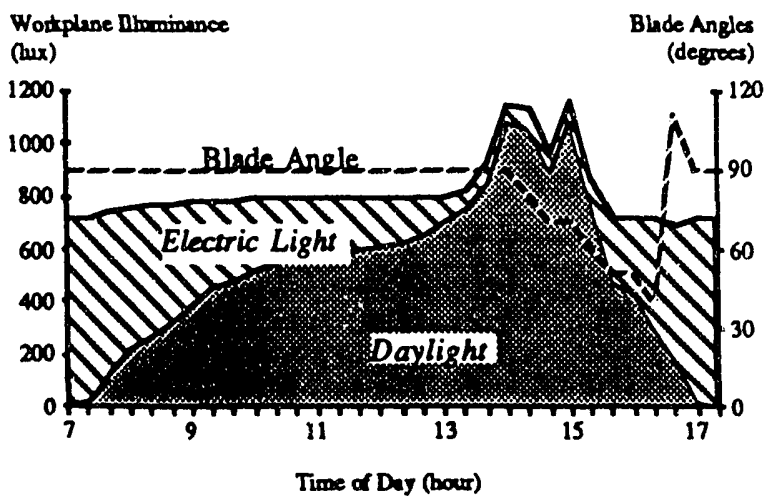

F. PROPORTIONAL CONTROL FROM FRONT FULLY SHIELDED SENSOR

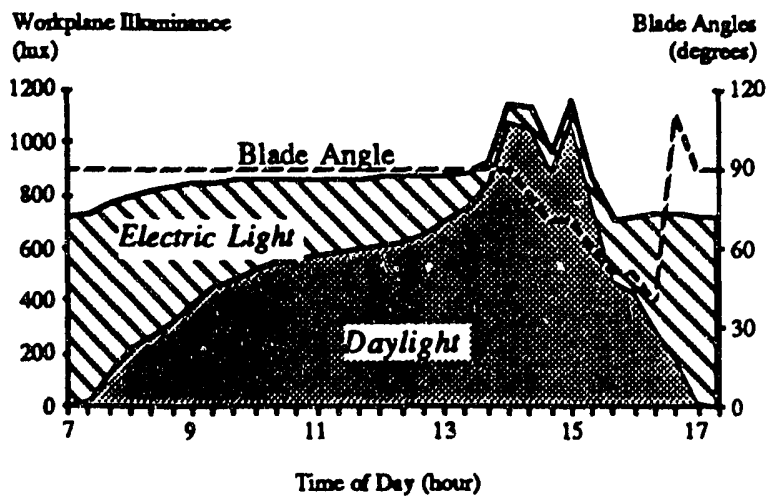

Figure 12. Light levels at front of room (station point WP4) for integral reset and closed-loop proportional control systems controlled by three photosensors for semi-infinite room model facing west (1/15/87). Target light level is 717 lux. 
A. INTEGRAL RESET CONTROL FROM REAR UNSHIELDED SENSOR

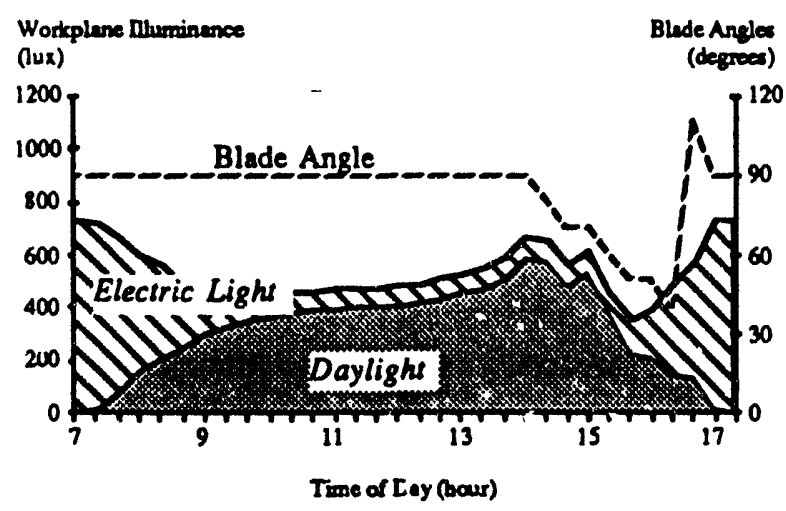

C. INTEGRAL RESET CONTROL FROM REAR PARTIALLY SHIELDED SENSOR

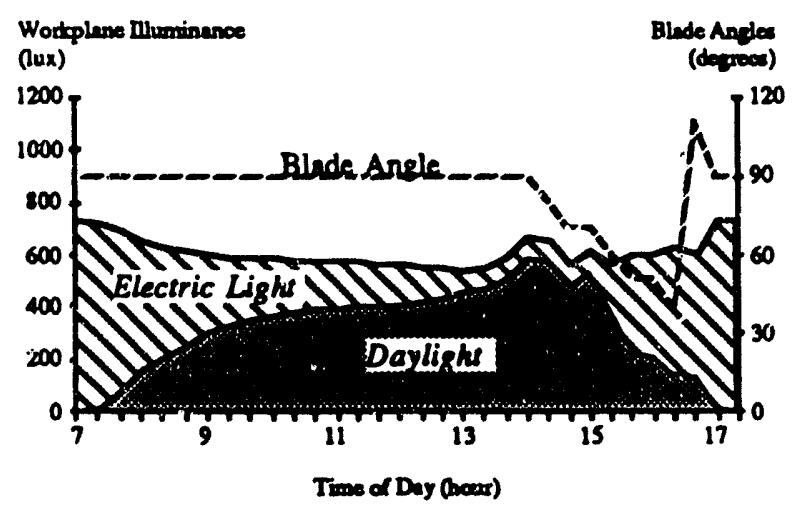

E. INTEGRAL RESET CONTROL FROM REAR FULLY SHIELDED SENSOR

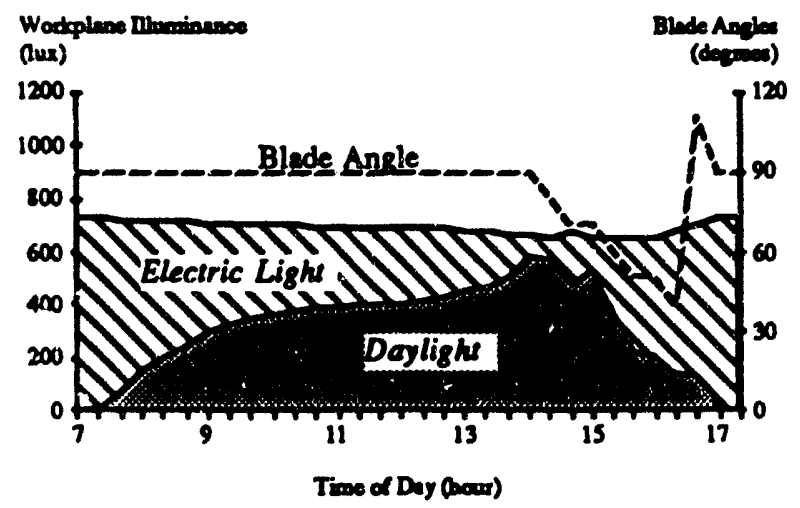

B . PROPORTIONAL CONTROL FROM REAR UNSHIELDED SENSOR

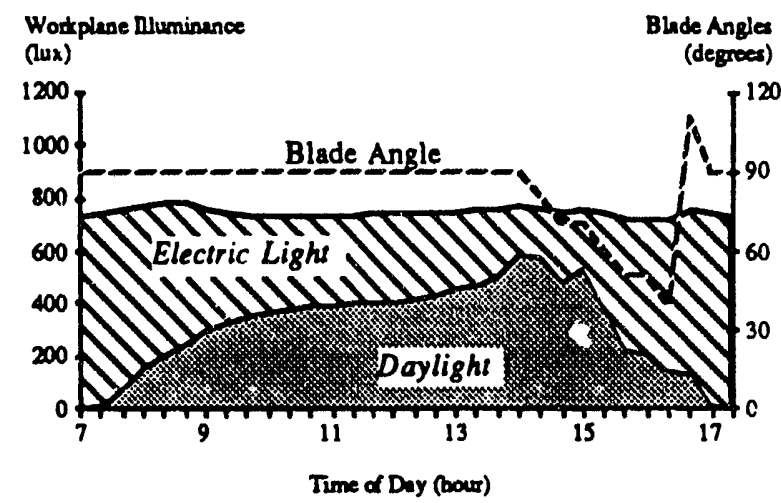

D. PROPORTIONAL CONTROL FROM REAR PARTIALLY SHIELDED SENSOR

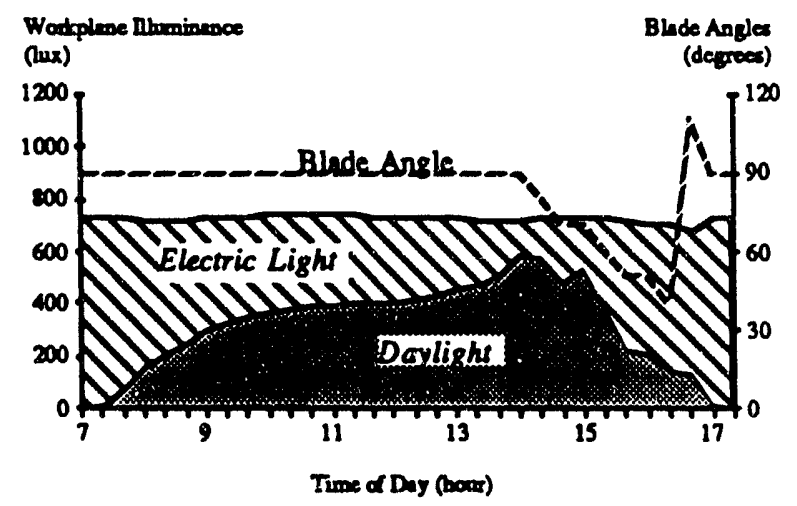

F. PROPORTIONAL CONTROL FROM REAR FULLY SHIELDED SENSOR

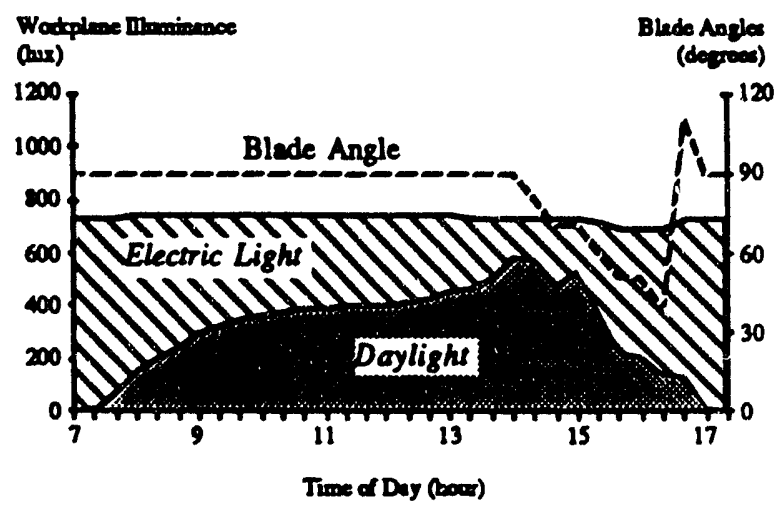

Figure 13. Light levels at rear of room (station point WP9) for integral reset and closed-loop proportional control systems controlled by three photosensors for semi-infinite room model facing west (1/15/87). Target light level is 736 lux. 
the blinds (i.e. periodically adjusting the venetian blinds to provide a reasonable external view while preventing uncomfortable direct sun from penetrating the room). A similar, but more refined control strategy was used for the semi-infinite room case. In this case, the blade angles could vary in $10^{\circ}$ rather than $30^{\circ}$ increments. Thus the light levels in the semiinfinite room are more indicative of what might be expected in a building with a completely automatic shading system designed to prevent direct solar penetration while providing maximum openness.

Small Office Model. The integral reset systems shown Figure 10 occasionally provide the requisite 720 lux at the task, but for much of the day supply considerably less electric lighting than required. Performance was worst for the $P_{\text {unsh }}$ photosensor but even when controlled by the $\mathrm{P}_{\mathrm{psh}}$ and $\mathrm{P}_{\mathrm{fsh}}$ photosensors, systems using the integral reset algorithm failed to provide sufficient electric light under most daylight conditions.

Semi-Infinite Room Model. In the rear portion of the semi-infinite room (Fig 13), integral reset controls exhibit similar relative performance as the small office model systems. The total illuminance at the back of the model was significantly below the design level (736 lux) when the integral-reset system was controlled by the rear unshielded photosensor, $P_{\text {bunsh. }}$. Improved performance was evident for integral reset systems controlled by the rear partially- and fully-shielded photosensors, $\mathrm{P}_{\mathrm{bpsh}}$ and $\mathrm{P}_{\mathrm{bfsh}}$. However, even in these cases, total illuminance at the rear of the room was slightly below the design level for substantial portions of the day.

In contrast to the results from the rear of the semi-infinite room, integral reset systems controlled by the front partially- and fully-shieiavd photosensors did provide sufficient electric light at the WP4 station point to meet the design illuminance level (717 lux) throughout the day (Figs. 12). The integral reset systems controlled by the front unshielded photosensor, $P_{\text {unsh }}$, however, provided substantially less illumination than required for many hours.

\section{Closed-Loop Proportional Control Systems}

Total light levels for $P_{\text {unsh, }}, P_{p s h}$, and $P_{f s h}$ using closed-loop proportional control are given in Figs 6-10 (winter) and 6-11 (summer) for the small office model facing west.

Analogous results for closed-loop proportional control systems in the semi-infinite room facing west are shown for the front and rear of the room, in Fig. 6-12 and Fig. 6-13, respectively.

The scale factors $M$ used in these simulations were calculated based on the assumption that the particular task-sensor daylight ratio obtained at the time of daytime calibration equalled b, our estimate of the generalized task-sensor daylight ratio for that senscr and condition. For the smail office model (see Table 2), the listed closed loop scale factors are calculated from the average of the b's computed for each test day. Scale factors for the semi-infinite room were calculated from the b computed for the single day (Table 3). Thus, the results 

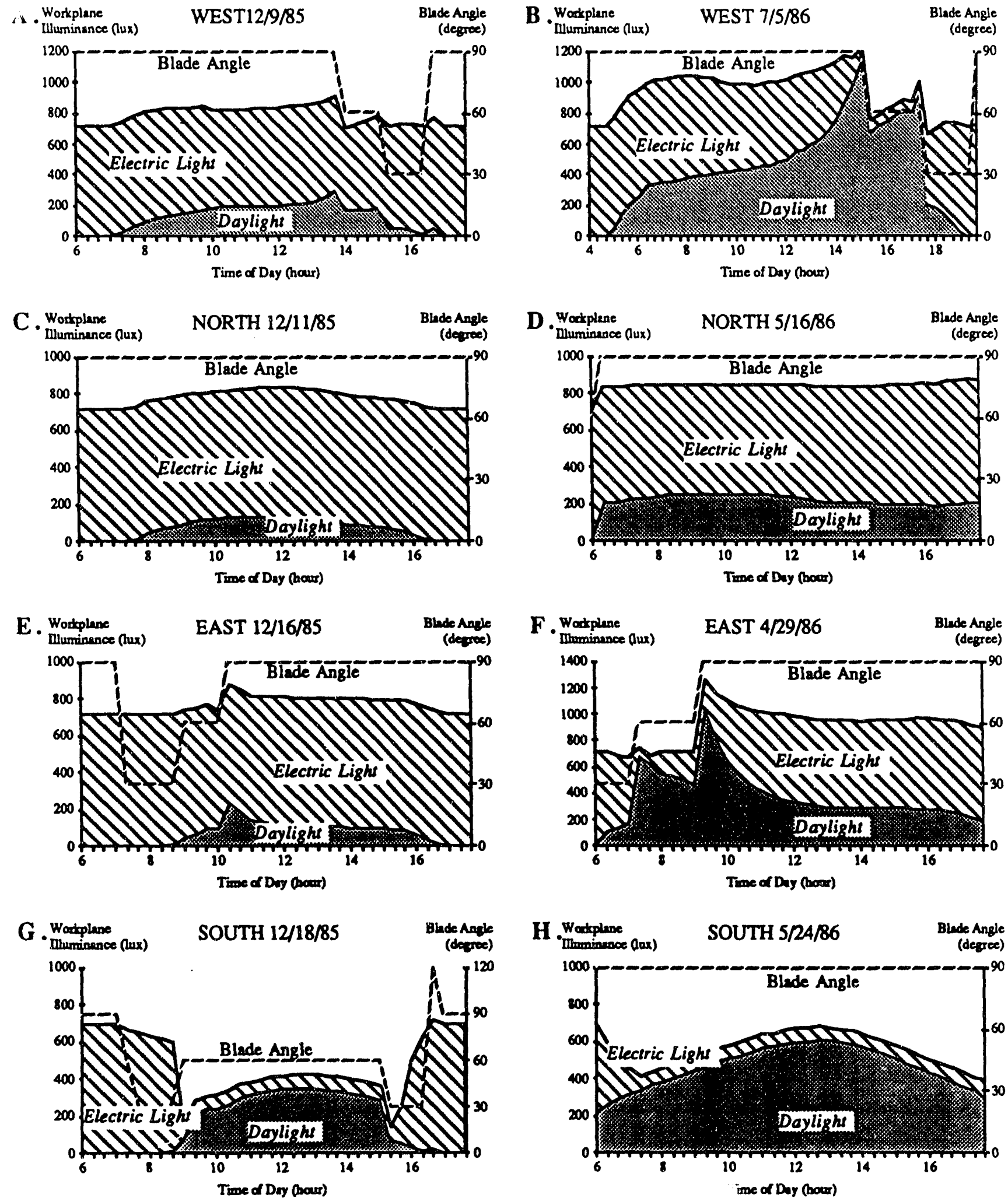

Figure 14. Light levels on workplane for open-loop proportional control systems controlled by window-aimed photosensor ior small office model model facing all directions (clear days). Target light level is 720 lux. 


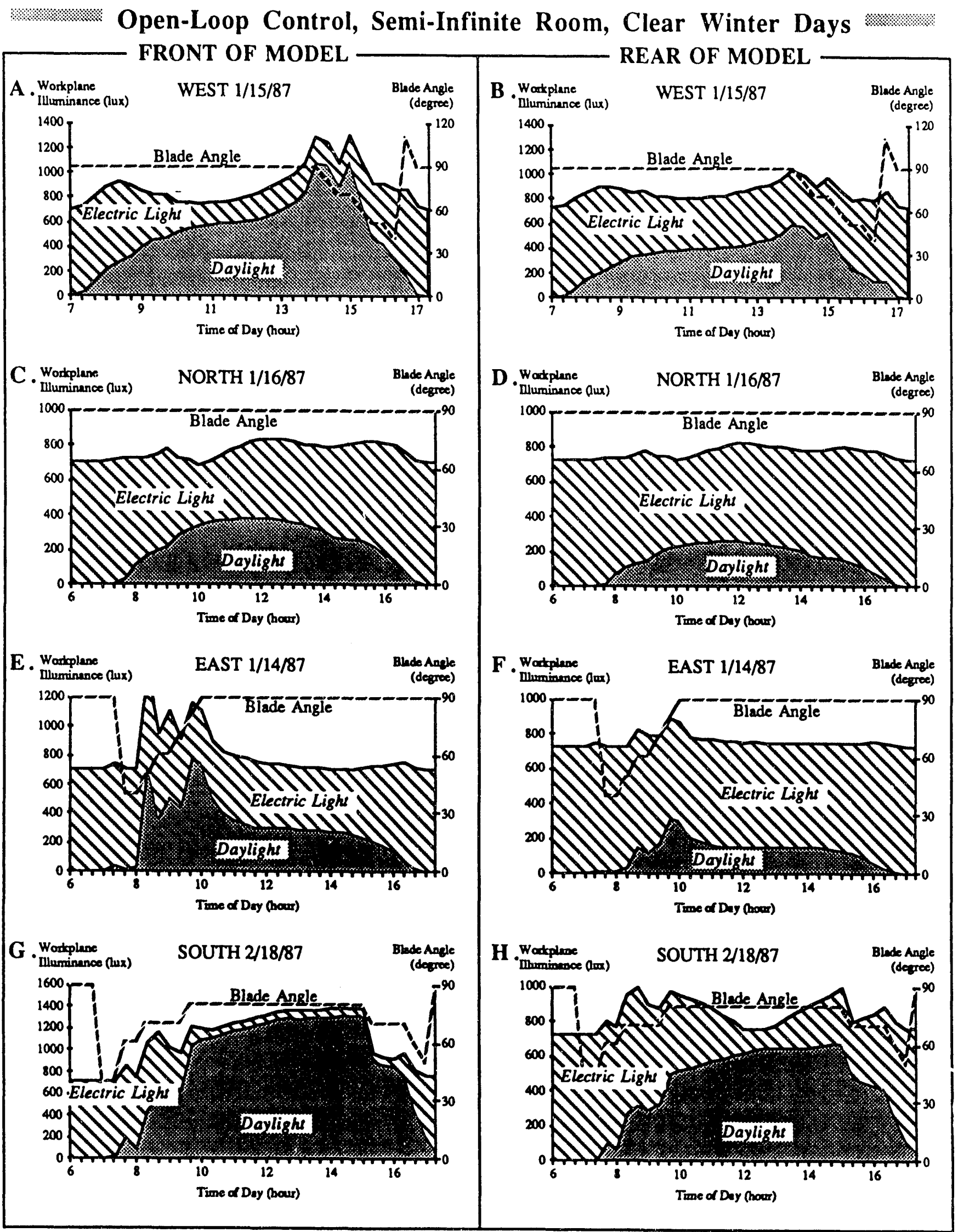

Figure 15. Light levels at front and rear station points for open-loop proportional control systems controlled by windowaimed sensor for semi-infinite room model facing all directions on clear winter and summer days. The target light level at WP4 and WP9 station points is 717 and 736 lux, respectively. 
presented below assume that each examined system was calibrated under "typical" daylight conditions as determined by the data given in Tables 2 and 3 .

Small Office Model. As shown in Fig. 10 and 11, the closed-loop proportional control systems controlled by $\mathrm{P}_{\mathrm{psh}}$ and $\mathrm{P}_{\mathrm{fsh}}$ perform almost ideally, providing just sufficient electric light to bring the total light at the task up to the target level. Furthermore, this control is maintained even when the venetian blind blade angles change drastically in the afternoon as the sun moves through the western sky. Although proportional control from the unshielded photosensor, $P_{\text {unsh, }}$ is clearly superior to integral reset, it is inferior to control using the $\mathrm{P}_{\mathrm{psh}}$ or $\mathrm{P}_{\mathrm{fsh}}$ systems. Unnecessarily high total light levels throughout the morning (especially for the summer day shown) is evidence of sub-optimal performance with $P_{\text {unsh. }}$

Semi-Infinite Room Model. The closed-loop proportional control simulations for the rear portion of the semi-infinite room are similar to the proportional control results for the small office model. At the front portion of the room, though, the proportional control and integral reset systems perform identically when controlled by the partially-or fully-shielded photosensors. With the unshielded photosensor there is a marked difference between proportional and integral reset control.

\section{Open-Loop Control}

The total task illuminances obtained with the $P_{w d w}$ photosensor driving an open-loop proportional control system is shown in Figs. 14 for all directions for the small office model in winter and summer. Fig. 15 shows the open-loop simulations for the $P_{w d w}$ photosensor in the semi-infinite room model. The graphs indicate that while open-loop proportional generally yields better results than integral reset control, there is a fair degree of variability in the maintained workplane light levels. In addition, the open-loop form of control provides more electric light than is necessary in some cases (for example, the westfacing small office model in summer, Fig. 14 B) while providing too little light in others (south, winter, Fig. 14 G). Similar results were found for the semi-infinite room.

\section{DISCUSSION}

The reason integral-reset systems typically perform much worse than proportional control systems is implied in the conditional expression given in Table 1. For an integral reset system to perform as desired requires that the task-sensor daylight ratio be equal to the task-sensor ratio for electric light. Given that the typical daylighting application has daylight entering through a side window and electric light coming from the ceiling, it follows that the relationship between the daylight at the task and photosensor output might be quite different than that for electric light. As we have shown, it is fortuitous to find a photosensor for which the daylight task-sensor ratio is equal to the electric light ratio. 
Looked at another way, recall that an integral reset system operates by maintaining a constant total amount of light on its control photosensor. It simply turns out that for most daylighting applications, maintaining a constant total amount of light on a ceiling-mounted sensor results in progressively lower total light levels at the workplane as daylight increases. To provide a constant light level at the task, then, we do not want the ceilingmounted photosensor signal to remain constant but rather to increase as the total light level in the space increases. A proportional control system does this by allowing the user to adjust the system sensitivity, $M$, during the daytime calibration.

Why do integral reset and closed-loop proportional control algorithms work equivalently well in the front of the semi-infinite model? Inspection of Table 1 shows that integral reset and closed-loop proportional control systems perform equally well only when the tasksensor ratio for daylight equals or exceeds that of electric light. If the ratios are exactly equal, then the closed-loop scale factor $\mathrm{M}_{C L}$ becomes infinite. But for infinite $\mathrm{M}$, the closed-loop proportional control transfer function becomes identical to the transfer function for integral reset control. Thus proportional control with an infinite scale factor is indistinguishable from integral rest control and the systems perform the same.

We have argued that open- and closed-loop proportional control systems perform significantly better than equivalent integral-reset systems because they allow adjustment of system sensitivity. It is tempting to assume that these open- and closed-loop proportional systems are therefore equivalent. But some important differences between the two algorithms favor the closed-loop control approach. The open-loop circuit designer configures the circuit so that full light output occurs when there is zero (or negligible) photosensor signal. To ensure that the photosensor will read nearly zero when the electric lights are on full at night, the manufacturer of an open-loop system must use a control photosensor that is insensitive to the electric light that it controls. On a practical level, this means that the field of view of an open-loop ceiling-mounted photosensor must be restricted to daylight coming through the window. A sensor designed in this way (such as $P_{w d w}$ ) will tend to be primarily sensitive to the brightness of the ground plane (i.e. the area of ground outside the controlled building space) and/or the venetian blinds, parameters that we have shown are not well correlated with interior workplane illuminance. Further work on the effects of varying ground plane reflectances under real sky conditions is required before we can determine the most appropriate spatial response for an open-loop photosensor.

For people in a position to specify controls, it is unfortunate that most control systems presently marketed for daylighting control are of the integral reset type. (A few manufacturers use open-loop proportional control instead). We can only speculate that the reason for this is that controls manufacturers have assumed that maintaining a constant signal from a ceiling-mounted sensor would result in constant light at the task. We have shown this assumption to be incorrect for practical photosensors. However, it can be 
shown that integral reset control is the correct approach for an entirely different lighting control strategy: lumen maintenance. (With lumen maintenance, the initially high light level ordinarily supplied by a new electric lighting system is dimmed to the maintained design level. Photo-electric control is then used to maintain this light level by gradually increasing input power as the electric lighting efficiency falls over the lighting maintenance cycle [7]). Thus integral reset control is not necessarily bad for all lighting control applications, but should be avoided in daylighting controls.

\section{CONCLUSION}

We have shown that the ability of daylight-linked lighting systems to provide a specified minimum light level at the task surface is influenced by 1) the control algorithm used, 2) the spatial response of the ceiling-mounted control photosensor and 3) the location of the photosensor relative to the task and light sources. Best performance was obtained with closed-loop proportional control using a photosensor with a large field of view but shielded from direct light from the window $\left(\mathrm{P}_{\mathrm{psh}}\right)$. This system was shown to provide the required design light level at selected workplane locations throughout the day regardless of room geometry or venetian blind position. Closed-loop proportional control was shown to require a one-time daylight calibration in order to adjust the system sensitivity to accommodate local lighting conditions.

The results show that an open-loop system controlled by the $\mathrm{P}_{\mathrm{wdw}}$ photosensor generally outperforms the integral-reset systems with respect to the control objectives. However, open-loop control found to be more erratic than closed-loop proportional control, with the open-loop system often significantly overshooting or undershooting the design level. The results suggest that sub-optimal performance with open-loop control is largely attributable to the necessity of using a photosensor that is uncoupled from the interior lighting environment.

Our results have demonstrated that the frequently-used integral-reset algorithm performs poorly in daylighting applications, but that performance can be improved somewhat by completely shielding the photocell from direct window light. Because of its many drawbacks, we do not recommend the integral reset algorithm for daylighting controls.

We found that the partially-shielded sensor $P_{\text {psh }}$ exhibited the best correlation between its output and the light level at the workplane point. The results also showed that the fullyshielded photosensor, $\mathrm{P}_{\mathrm{fsh}}$, did not exhibit as good a correlation, which indicates that shielding a ceiling-mounted control photosensor from walls other than the window-wall does not improve tracking capability. We found that the relationship between workplane illuminance and photosensor signal for the $\mathrm{P}_{\text {unsh }}$ photosensor was less well correlated than either the partially or fully-shielded photosensors except in the rear of the semi-infinite room model when all three sensors performed roughly equally well. 
This work has shown that photo-electrically controlled lighting systems will only provide good results if specifiers are careful to match the control algorithm to the desired strategy. If daylighting strategies are to realize their potential for saving energy and reducing peak demand loads, manufacturers and designers must make certain that the correct type of control is selected for the application.

\section{REFERENCES}

[1] D.R.G. Hunt and V.H.C. Crisp, "Lighting Controls: Their Current Use and Possible Improvement," International Journal of Energy Research, vol. 2, no. 4, pp. 343-374, 1978.

[2] A. Levy, "Lighting Controls, Patterns of Lighting Consumption, and Energy Conservation," IEEE Transactions on Industry Applications, vol. IA-16, no. 3, pp. 419-427, 1980.

[3] F. Rubinstein and M. Karayel, "The Measured Energy Savings from Two Lighting Control Strategies," IEEE Transactions on Industry Applications, vol. IA-20, no. 5, pp. 1189-1197, 1984.

[4] V.H.C Crisp, "Energy Conservation in Buildings: A Preliminary Study of the Use of Automatic Daylight Control of Artificial Lighting," Lighting Research \& Technology, vol. 9, no. 1, pp. 31-41, 1977.

[5] F. Rubinstein, "Photoelectric Control of Equi-illumination Lighting Systems," Energy and Buildings, vol. 6, pp. 141-150, 1984.

[6] "Photo-electric Control of Daylight-Following Lighting Systems", Final Report for Electric Power Research Institute, RP 2285-03, July, 1987.

[7] J. Kaufman, Handbook of the Illuminating Engineering Society, Applications Volume, New York, 1987.

\section{ACKNOWLEDGMENTS}

This work was funded by the Electric Power Research Institute under Contract No. RP2285-3. We wish to acknowledge and thank the Electric Power Research Institute for their support of this work, especially the contributions of Mr. Gary Purcell, Mr. Stephen Pertusiello, Mr. James Jewell, Dr. Arvo Lannus, and Mr. Karl Johnson. This manuscript draws heavily on the RP2285-3 final report prepared by the authors for EPRI.

Additional support was also provided by the Assistant Secretary for Conservation and Renewable Energy, Office of Buildings and Community Systems, Building Equipment Division of the U.S. Department of Energy under Contract No. DE-AC03-76SF00098. 


\section{APPENDIX A.}

Below, we derive, for daylighting systems, equations for each control algorithm that expresses the total light level at the task as a function of the daylight component of the photosensor signal and daylight on the task.

Since the illumination at the task and at the photosensor at any time $t$ is simply the sum of the respective daylight and electric light components, we can write:

$$
S_{T}(t)=S_{D}(t)+S_{E}(t)
$$

and

$$
I_{T}(t)=I_{D}(t)+I_{E}(t)
$$

If we assume that the electric lighting is controlled so that all the lights within the controlled space dim uniformly then we can make two important simplifications:

$$
\begin{aligned}
& S_{E}(t)=\delta(t) S_{E m} \\
& I_{E}(t)=\delta(t) I_{E m}
\end{aligned}
$$

The above equations may be interpreted to mean that the luminance distribution from electric light remains constant regardless of the actual dimming level $\delta(t)$. Note that these equations would nin be true in a room where the electric lights nearer the window could, for example, dim more than the lights at the back of the room. Such lighting systems require a more sophisticated mathematical treatment than that presented here.

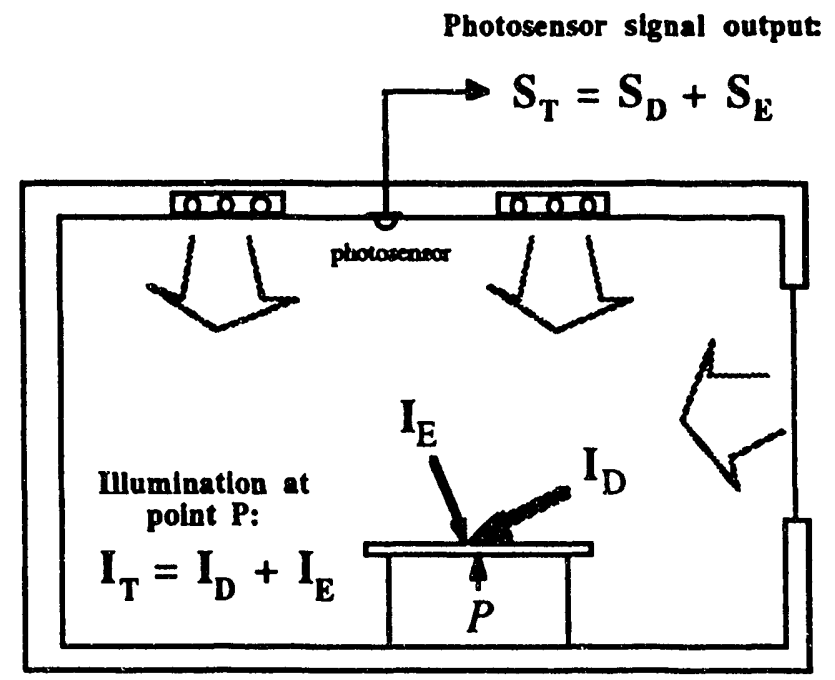

Figure A-1. Cross section of daylit room showing window and photosensor

If the photosensor is located inside the controlled space, as shown in Figure A-1, and is to be susceptible to the electric light that it controls then the integral-reset or closed-loop proportional control algorithms would be used. If, on the other hand, the photosensor is outside the controlled space (or inside but shielded from 
electric light) so that it can detect only daylight, then the system would use the open-loop proportional control algorithm.

The three following sections contain derivations of the governing equations for the three algorithms. First, the algorithm is defined in terms of its corresponding control circuit. This is equivalent to specifying an output-level function. This function is then used to obtain equations for the workplane illuminance in terms of time-dependent daylight conditions. These equations are the mathematical basis of simulation programs we use to predict control system response based on the daylight information collected from the scale model.

\section{Integral-Reset}

An integral-reset system continually adjusts the light output, $\delta$, to keep the photosensor signal, $S_{\mathrm{T}}(t)$, at a preset reference level. Figure A-2 shows a simplified integral-reset control circuit. The control photosensor output is fed into the summing node of a simple operational amplifier integrator circuit. If the lighting system is to provide full light output at night, which is usually the case, the control circuit is calibrated at night with the electric lights at full power and the sepoint adjusted until the photosensor input generated under these conditions $\left(\mathrm{S}_{\mathrm{Em}}\right)$ is appropriately nulled. Increasing daylight in the space (and on the photosensor) will drive the inverting input high, causing the op-amp output to drop at a rate determined by the circuit capacitances and resistances. This in turn causes the electric lights to dim, reducing the photosensor output and the jential at the inverting input until it once again matches the setpoint level. The circuit shown has effectively infinite $\mathrm{DC}$ gain.

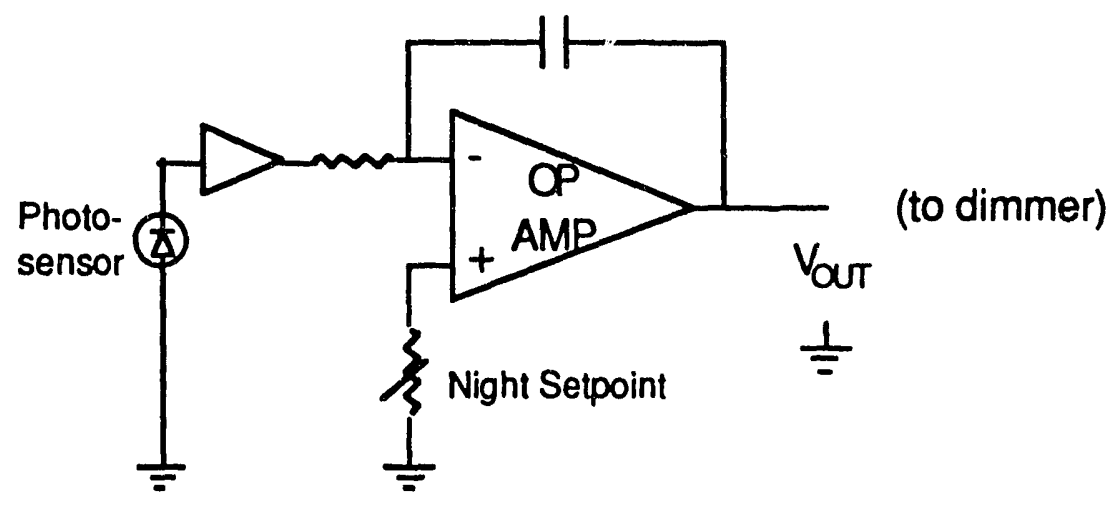

Figure A-2. Generic circuit diagram of integral reset control

Assuming it is calibrated at night as described above, an integral-reset system operating in its dynamic range is defined by the following expression:

$$
S_{T}(t)=S_{E m}
$$

Applying Eqs. 1 and 3 to Eq. 5 , one can solve for $\delta$ in terms of the independent variable $S_{D}(t)$ :

$$
\delta=1-\frac{S_{D}(t)}{S_{E m}} \quad 0 \leq S_{D}(t) \leq\left(1-\delta_{\min }\right) S_{E m}
$$

Eq. 6 describes the dependence of $\delta$ on $S_{D}(t)$ for an integral-reset system operating in its dynamic range. For $S_{D}(t)$ larger than $\left(1-\delta_{\min }\right) S_{E m}$, the system will provide minimum light output:

$$
\delta=\delta_{\min } \quad S_{D}(t)>\left(1-\delta_{\min }\right) S_{E m}
$$


If $S_{D}(t)$ is in the range covered by Eq. 7 , then the system is no longer in its operating range. Substituting Eqs. 2 and 4 into Eqs. 6 and 7, one can solve for the total illuminance at the workplane in terms of $I_{D}(t)$ and $S_{T}(t):$

$$
\begin{array}{lr}
I_{T}(t)=I_{E}(t)+I_{E m}\left(1-\frac{S_{D}(t)}{S_{E m}}\right) & 0 \leq S_{D}(t) \leq\left(1-\delta_{\min }\right) S_{E m} \\
I_{T}(t)=I_{D}(t)+\delta_{\min } I_{E m} & S_{D}(t)>\left(1-\delta_{\text {min }}\right) S_{E m}
\end{array}
$$

\section{Open-Loop Proportional Control}

Open-loop proportional control is defined as a system for which the light output is a linear function of the photosensor signal:

$$
\delta=\mathrm{MS}_{\mathrm{T}}(\mathrm{t})+1
$$

A simplified circuit diagram for the open-loop system is shown in Figure A-3. The control photosensor output is fed into the summing node of a negative-feedback, variable-gain operational amplifier. This circuit is designed assuming that a zero signal on the inverting input corresponds to full light output. Using a photosensor that is insensitive to electric light ensures that $S_{\mathrm{Em}} \approx 0$ as required. The gain of the amplifier is adjusted by varying the value of the feedback resistor (equivalent to changing $\mathrm{M}$ in $\mathrm{Eq} .10$ ) under appropriate daylight conditions. Calibrating the system during the day allows the user to tailor the system's gain to prevailing daylight and room conditions.

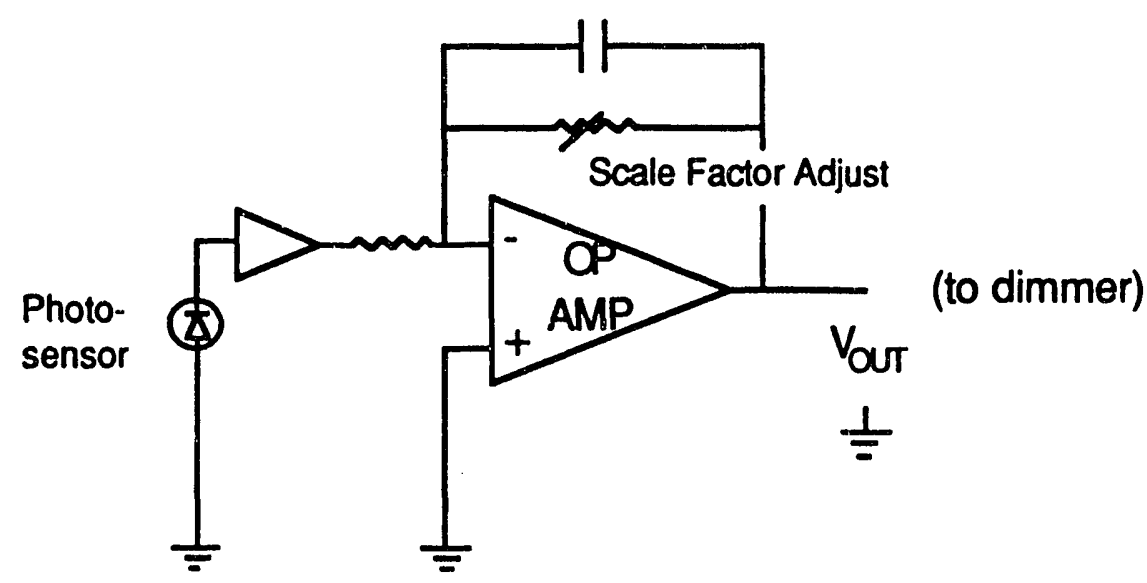

Figure A-3. Generic circuit of open-loop proportional control

Applying Eqs. 1 and 3 to Eq. 10 and solving for $\delta$, one obtains:

$$
\delta=\frac{M S_{D}(t)+1}{1-M S_{E m}} \quad 0 \leq S_{D}(t) \leq \frac{\delta_{\min }\left(1-M S_{E m}\right)-1}{M}
$$

and 
$\delta=\delta_{\min }$

$S_{D}(t)>\frac{\delta_{\min }\left(1-M S_{E m}\right)-1}{M}$

Assuming that the system is calibrated so that the total light level provided at the task matches the design level at the time of calibration, $L_{c}$, we can solve for the system gain $M$ in terms of the prevailing daylight conditions. Substituting Eq. 3 into:

$$
I_{T}\left(t_{c}\right) \equiv I_{E m}=I_{D}\left(t_{c}\right)+I_{E}\left(t_{c}\right)
$$

and using Eq.11 yields:

$$
M=\frac{I_{D}\left(t_{c}\right)}{I_{D}\left(t_{c}\right) S_{E m}-I_{E m} S_{E m}-I_{E m} S_{D}\left(t_{c}\right)}
$$

The photosensor for an open-loop system must be much more sensitive to daylight than electric light. Consequently, the first two terms in the denominator in Eq.13 are much smaller than the third term and, to first order, the system gain $M$ is proportional to the ratio $I_{D}\left(t_{C}\right) / S_{D}\left(t_{C}\right)$.

To obtain expressions for total illuminance at the workplane for open-loop systems, Eqs. 11 and 12 are used with Eqs. 2 and 4 to obtain:

$$
\begin{array}{ll}
I_{T}(t)=I_{D}(t)+I_{E m} \frac{M S_{D}(t)+1}{1-M S_{E m}} & 0 \leq S_{D}(t) \leq \frac{\delta_{\min }\left(1-M S_{E m}\right)-1}{M} \\
I_{T}(t)=I_{D}(t)+\delta_{\min } I_{E m} & S_{D}(t)>\frac{\delta_{\min }\left(1-M S_{E m}\right)-1}{M}
\end{array}
$$

\section{Closed-Loop Proportional Control}

A closed-loop proportional control system adjusts the electric light level so that $\delta(t)$ is a linear function of the difference between $\mathrm{S}_{\mathrm{T}}(\mathrm{t})$ and $\mathrm{S}_{\mathrm{Em}}$ :

$$
\delta=M\left(S_{T}(t)-S_{E m}\right)+1
$$

A simplified circuit diagram for the closed-loop proportional control system is given in Figure A-4. This circuit is similar to the open-loop circuit in that the control photosensor output is fed into the summing node of a negative-fecdback, variable-gain operational amplifier. However, unlike the OLC circuit, which permits adjustment only of the system gain, the closed-loop proportional control circuit permits adjustments of both system gain and the offset on the noninverting input. During daytime operation, the output from the control photosensor drives the inverting input high. The op amp will produce whatever output is required to keep the potential at the inverting input equal to the potential at the non-inverting input. The relative change in op amp output for a given change in photosensor input is governed by the values of the feedback resistor (and other circuit resistances). 


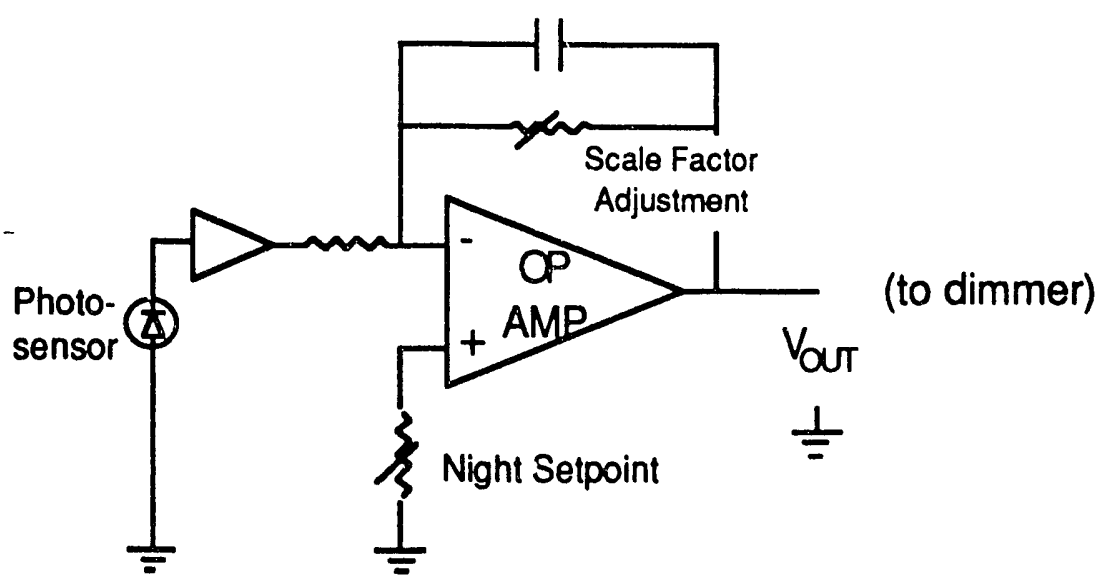

Figure A-4. Generic circuit of closed-loop proportional control

Closed-loop proportional control is similar to open-loop proportional control except that the former permits adjustment of both the system gain $(M)$ and the nighttime offset level $\left(S_{\mathrm{Em}}\right)$. To express $\delta$ as a function of the independent parameter $S_{D}(t)$, we substitute Egss. 1 and 2 into Eq. 16. Rearranging and solving for $\delta$ yields:

$$
\delta=\frac{1+M\left(S_{D}(t)-S_{E m}\right)}{1-M S_{E m}} \quad 0 \leq S_{D}(t) \leq \frac{\delta_{\min }\left(1-M S_{E m}\right)-1}{M}+S_{E m}
$$

When $S_{D}(t)$ exceeds the range given in Eq. $17, \delta$ is simply given by:

$$
\delta=\delta_{\min }
$$

$$
S_{D}(t)>\frac{\delta_{\min }\left(1-M S_{E m}\right)-1}{M}+S_{E m}
$$

As in the open-loop control case, the value of $M$ in the above expressions is determined by calibrating the response of the lighting system during the day. Assuming that the lighting is calibrated so that at the time of calibration, $t_{c}$, the design level $\mathrm{I}_{\mathrm{Em}}$ is obtained at the task, one can solve for $\mathrm{M}$ in terms of the daylight conditions obtained at $t_{c}$ using Eqs. 2 and 4 with Eq. 17:

$$
M=\frac{I_{D}\left(t_{c}\right)}{I_{D}\left(t_{c}\right) S_{E m}-I_{E m} S_{D}\left(t_{c}\right)}
$$

Finally, to obtain the total illuminance at the workplane for the closed-loop proportional control system, we use Eqs. 2 and 4 with Eqs. 17 and 18 to obtain:

$$
I_{T}(t)=I_{D}(t)+I_{E m} \frac{1+M\left(S_{D}(t)-S_{E m}\right)}{1-M S_{E m}} \quad 0 \leq S_{D}(t) \leq \frac{\delta_{\min }\left(1-M S_{E m}\right)-1}{M}+S_{E m}
$$




$$
\mathrm{I}_{\mathrm{T}}(\mathrm{t})=\mathrm{I}_{\mathrm{D}}(\mathrm{t})+\mathrm{I}_{\mathrm{Em}} \delta_{\min }
$$$$
S_{D}(t)>\frac{\delta_{\text {min }}\left(1-M S_{E m}\right)-1}{M}+S_{E m}
$$ 

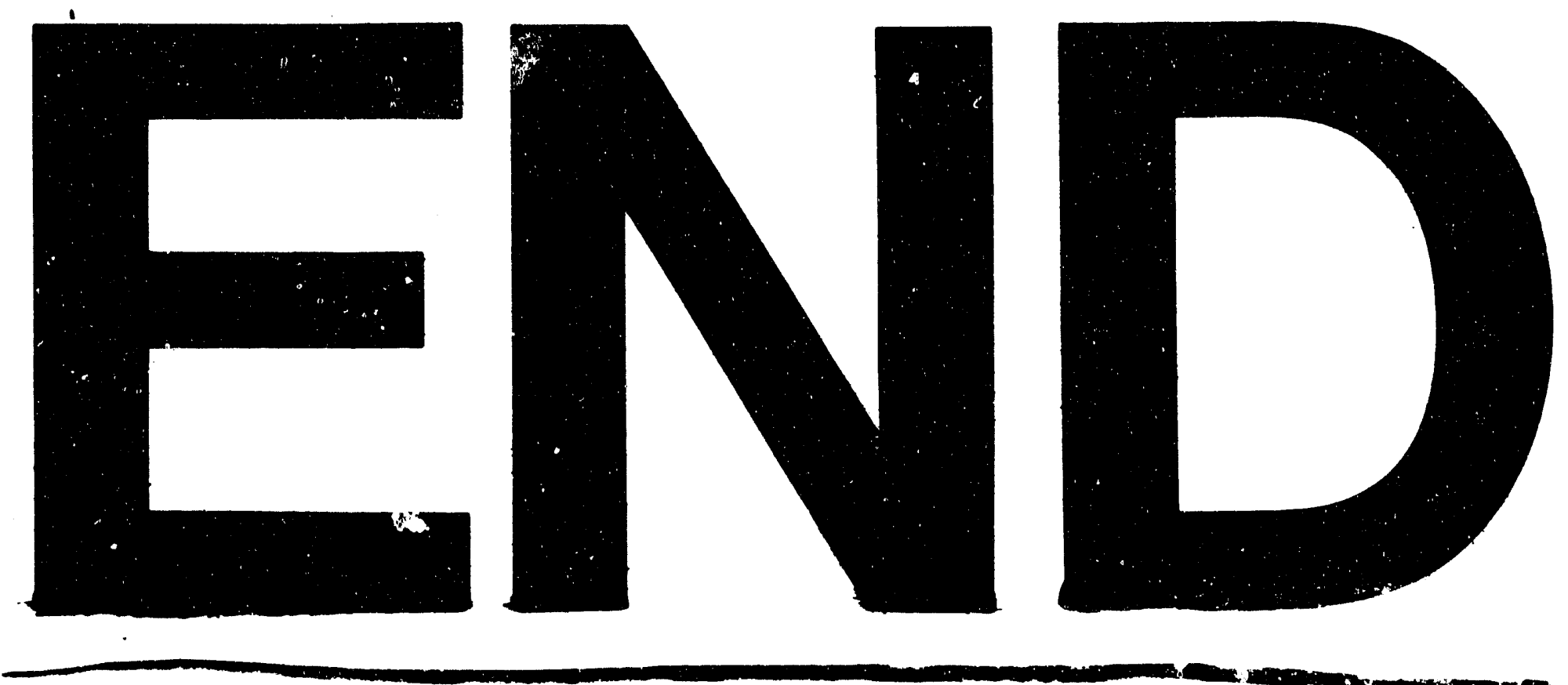
